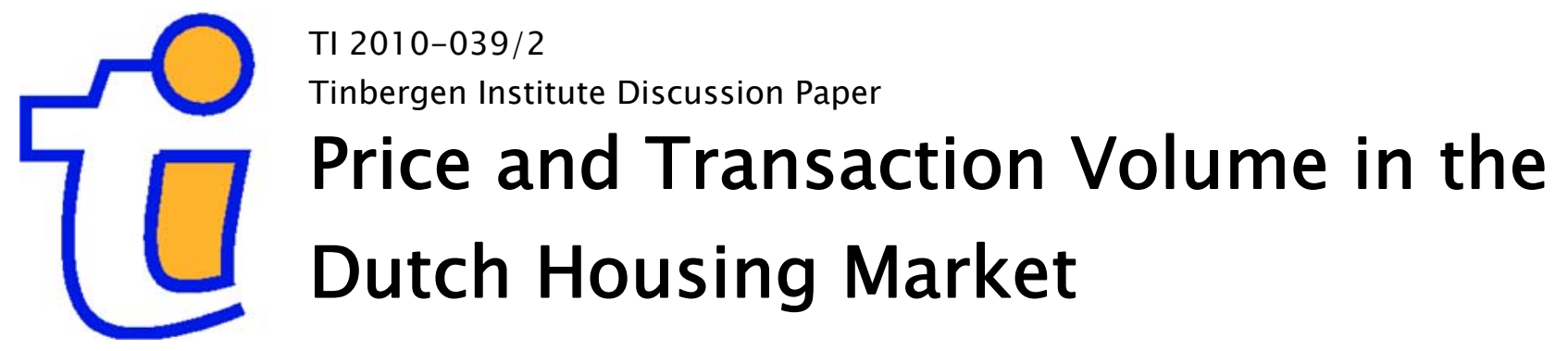

Erik R. de Wit ${ }^{1,2}$

Peter Englund 3,1

Marc Franckel

1 University of Amsterdam;

2 Tinbergen Institute;

${ }^{3}$ Stockholm School of Economics. 


\section{Tinbergen Institute}

The Tinbergen Institute is the institute for economic research of the Erasmus Universiteit Rotterdam, Universiteit van Amsterdam, and Vrije Universiteit Amsterdam.

Tinbergen Institute Amsterdam

Roetersstraat 31

1018 WB Amsterdam

The Netherlands

Tel.: +31(0)205513500

Fax: $+31(0) 205513555$

Tinbergen Institute Rotterdam

Burg. Oudlaan 50

3062 PA Rotterdam

The Netherlands

Tel.: + $31(0) 104088900$

Fax: $+31(0) 104089031$

Most TI discussion papers can be downloaded at http://www.tinbergen.nl. 


\title{
Price and Transaction Volume in the Dutch Housing Market
}

\author{
Erik R. de Wit \\ University of Amsterdam and Tinbergen Institute \\ (e.r.dewit@uva.nl) \\ Peter Englund \\ Stockholm School of Economics and University of Amsterdam \\ (peter.englund@hhs.se) \\ Marc Francke \\ University of Amsterdam \\ (m.k.francke@uva.nl)
}

January 2010

\begin{abstract}
Housing markets typically exhibit a strong positive correlation between the rate of price increase and the number of houses sold. We document this correlation on high-quality Dutch data for the period 1985-2007, and estimate a VEC-model that allows us to study the mechanism giving rise to the correlation. The data identify the flows of new houses offered for sale as well as the number of houses sold. According to the estimated model, shocks to market fundamentals (the mortgage rate) have an immediate and significant impact on the rate of sale, little impact on the rate of entry of new houses for sale, and a gradual impact on the house prices. This pattern is consistent with a search model where buyers and sellers gradually learn about changes in market conditions.
\end{abstract}

Acknowledgements: Earlier versions of this paper has been presented at UC Berkeley, University of Amsterdam, London School of Economics, the 2009 ASSA Meetings in San Francisco and the 2009 ERES Conference in Stockholm. We received constructive comments from many participants, in particular François Ortalo-Magné and Carles Vergara-Alert. The first version of the paper was written when Peter Englund was visiting the Fisher Center for Real Estate at UC Berkeley. We benefited from financial support from the Amsterdam School of Real Estate (ASRE).The data base was made available by the Dutch Association of Real Estate Brokers and Real Estate Experts (NVM). We are very grateful for all support. 


\section{Price and Transaction Volume in the Dutch Housing Market}

\section{Introduction. Price-volume correlations}

Between the mid 1980s and today real house prices more or less doubled in most industrialized countries. This has not been a smooth and continuous process. All countries experienced cycles where booms with price increases above trend were followed by busts with stagnating or falling prices. But price fluctuations alone do not fully characterize fluctuations in the housing market. In price booms, the market is typically also more liquid with frequent transactions and houses selling quickly, whereas in busts there are fewer sales and many houses remain on the market for a long time. Since the housing stock is fixed in the short run and most transactions are driven by households moving from one home to another, i.e. being present more or less simultaneously on both sides of the market, this is something of a puzzle. Figures 1 and 2 illustrate this pattern for the Dutch market for owner-occupied homes, based on the data being analyzed in this paper. Peaks and troughs of the number of sales and price changes coincide clearly in some periods (e.g. the trough in 1995 and the peak in 1999). Over other periods, however, the correlation appears to be week. Once we relate sales to the number of houses for sale there is a much stronger correlation. Figure 2 shows that the rate of sale (sales divided by houses on the market) and price changes follow each other very closely (the correlation coefficient is 0.71 ).

Two main mechanisms have been advanced to explain the price-volume correlation. One is couched in standard demand-and-supply terms and associates more transactions with higher aggregate demand, e.g. because of released credit constraints that trigger moves up the housing ladder. The other approach emphasizes that the housing market is a search market where prices fail to clear the market at every instant and fluctuations in the number of sales primarily reflect changes in time-on-the-market rather than in underlying fundamentals.

Previous empirical studies have largely been confined to looking at data on prices and the number of sales, thereby being unable to assess the relative explanatory power of these two approaches to understanding the price-quantity correlation. In this paper we analyze detailed Dutch data that allow us to go behind number of sales and transaction prices. Market developments reflect the decisions of thousands of homeowners to offer their houses for sale 
and to set a reservation price that they are prepared to accept. At the same time, prospective homebuyers shop around for good deals. Given the search nature of the market, it does not clear continuously and variations in the time on the market and the rate of sale may accommodate inertia in prices. To understand the price-quantity correlation, it is therefore important to identify the flows of houses offered for sale as well as those sold, and to distinguish list prices set by sellers and sales prices accepted by both parties.

The data set analyzed in this paper is rich enough to contain observations on these variables for the entire Dutch housing market over a period of more than 20 years. For nearly two million dwellings sold between 1985 and 2007, we observe the original list price and the date when the dwelling was put on the market as well as the final sales price and the date of sale. This allows us to distinguish between the rate of entry of new houses onto the market - which would be the key variable if variations were due to underlying demand-and-supply fluctuations - and the rate of sale of houses on the market - which is an important indicator in a search market. Further, we may investigate any differences between the pattern of list prices - reflecting buyer information and beliefs of market conditions - and sales prices - reflecting both seller and buyer information. Beyond providing descriptive statistics on these variables, we use our data to estimate a dynamic model of the Dutch housing market where prices and quantities are driven by disturbances to fundamental demand factors.

A main finding is that price changes are strongly positively correlated with the rate of sale but much more weakly correlated with the rate of entry of new dwellings for sale. We take this as prima facie evidence in favor of a search story over a demand-and-supply story. This is further corroborated by our estimates of the dynamic model. It shows that shocks to demand the real mortgage rate - have an immediate but temporary impact on the rate of sale, a gradual and permanent impact on prices (both list price and sales price) and little impact on the rate of entry.

The next Section of our paper reviews the empirical literature on the price-quantity correlation. Various theoretical explanations for this correlation have been advanced. In Section 3 we briefly discuss the main candidates: the interaction between credit constraints and demand and supply, search - in particular combined with gradual adjustment of expectations - and loss aversion. Specifically, we discuss the observable implications of each theory. Next we present the data and some descriptive statistics in Section 4. Our empirical 
analysis is based on a vector-error-correction model. The model is specified in Section 5 and the estimation results, primarily in the form of impulse-response functions, are presented in Section 6. We conclude in Section 7 that the results are consistent with the search-gradualadjustment view but not with the credit-constraint theory.

\section{The empirical evidence}

The positive correlation between price changes and transaction volumes in housing markets is by now a relatively well established empirical regularity ${ }^{1}$, primarily for US data but also for the UK and Sweden. In fact, realtors and other market actors seem to take the fluctuation between hot and cold markets - differing both in price development and sales activity - as a basic fact of life. While this general pattern is confirmed by most studies, the empirical picture is not without ambiguity. Some authors have looked at the simple correlation between price changes and number of sales. An early paper by Miller and Sklarz (1986), based on condominium data from Hawaii, shows that the rate of sale in one quarter is positively related to the price change in the next quarter; sales predict price changes. Two influential theoretical papers include a look at aggregate US data. Stein (1995) reports a significant relation between current sales volume and last year's rate of price change, i.e. a temporal lag in the opposite direction to that found by Miller and Sklarz. Berkovec and Goodman (1996) regress the change in median sales price on the simultaneous change in turnover, again with a significantly positive coefficient.

Other papers analyze dynamic econometric models with more structure. Follain and Velz (1995) find, counter to most other papers, price and sales volume to be negatively correlated when put in the context of a structural model of housing market adjustment. Two papers study European housing markets. Hort (2000) finds no consistent relation between price changes and turnover changes using panel data for local housing markets in Sweden. Fixed effects regression on sales against the house price level yields negative coefficients at all frequencies. Hort goes on to investigate how shocks to fundamentals (represented by the after-tax mortgage rate) are transmitted into house prices and sales. Based on a VAR-model she concludes that an interest shock has an immediate negative impact on sales but affects prices

\footnotetext{
${ }^{1}$ In contrast, commercial property markets do not appear to exhibit a price-volume correlation according to a study by Leung and Feng (2005) on Hong Kong office buildings.
} 
only gradually. More recently, Andrew and Meen (2003) study aggregate UK data focusing on the adjustment to fundamentals within an error-correction framework. In a first stage, they estimate a long-run levels relation between price and fundamentals represented by income, supply, the number of households and construction costs. In the second stage, a two-equation conditional VAR-model is estimated where price change and the number of sales (as a fraction of the stock) are driven by deviations from equilibrium (the residuals of the first-stage equation). The results indicate that a shock to fundamentals impacts on sales and prices in the same direction. The sales effect peaks after about a year and sales revert back to their original equilibrium level after a couple of years. Prices, on the other hand, continue to fall for more than two years before turning and oscillating back towards the new equilibrium level.

Recent unpublished papers estimating dynamic models of price-sales adjustment include Clayton et al. (2008) and Wheaton and Lee (2009), both based on panel data of US local housing markets. Wheaton and Lee find that much of the variation in turnover is due to flows between rental and owner-occupied housing. In a search market context, one would also expect to see a connection between price volatility and turnover: the more uncertainty the higher should be reservation prices and the longer houses should stay on the market before being sold. Consistent with this Tu, Ong and Han (2009) find a negative correlation between volatility and turnover in their analysis of data on Singapore condominiums.

The papers reviewed above typically look at correlations at quarterly or yearly frequencies. Interestingly, there also seems to be a correlation in seasonal patterns. Ngai and Tenreyro (2009) document, both for US and UK data, that house price increases are systematically larger over the summer season (second and third quarters) than during the winter (fourth and first quarters). ${ }^{2}$ The difference is substantial, on the order of 5 percent annualized.

Correspondingly, there is also a seasonal pattern in sales with increases during summer and decreases during winter. They also develop a search model of the housing market, where exogenous seasonal variations in mobility (e.g. related to the school year and moving costs) give rise to systematically higher prices in the summer due to improved matching between sellers and buyers (thick market effects).

\footnotetext{
${ }^{2}$ In contrast, a study on local UK housing prices by Rosenthal (2006) reports seasonal effects that are statistically insignificant in most cases.
} 


\section{Theories and empirical implications}

There is no shortage of theories to account for the correlation between price and volume in housing markets. Broadly speaking one can identify three groups of theories. One theory focuses on the interaction between downpayment constraints, mobility and housing prices. Fundamental factors impact on demand and prices thereby releasing or tightening downpayment constraints, which will have a feedback effect on mobility and thereby on prices and the number of houses sold. A second set of theories regards the housing market as a search market that fails to clear instantaneously. A third theory suggests behavioral explanations for the price-quantity correlation. For example, if homeowners are loss averse and hence reluctant to lower asking price below the original purchase price, then the number of sales will decrease in a weak market. These theories are not mutually exclusive but can be combined with each other.

The link between credit constraints and the price-quantity correlation was first highlighted by Stein (1995). In his model the housing consumption of some households is restricted by downpayment requirements. A positive shock to fundamentals will increase housing prices thereby improving the equity position of incumbent homeowners and allowing them to trade up to a larger house. This would tend to increase mobility and transaction volume and thereby cause a further increase of prices and the volume of transactions. Conversely, a negative shock would depress prices and lock-in households and initiate a downward price spiral with even more households locked-in due to shortage of equity. Stein's argument is not developed within an explicit equilibrium model. This step was taken in the papers by Ortalo-Magné and Rady $(1999,2006)$, which integrate downpayment constraints within an overlappinggenerations-model, where households move from starter homes to trade-up homes depending on income shocks and funding possibilities in the capital market. These models highlight the role of demographic factors like the relative size of different generations. They also have implications for variations in the relative prices of small and large houses. A key empirical implication is the feedback effect between price and quantity that arises as price changes strengthen or weaken credit constraints. Higher prices increase home equity and allow homeowners to afford the downpayment for a larger house. In an equilibrium setting with some households climbing up the market if they can afford, this model generates a positive correlation between sales (the fraction of households moving) and prices. ${ }^{3}$

\footnotetext{
${ }^{3}$ In Ortalo-Magné and Rady (1999) households can also move between owning and renting.
} 
In these models causation runs from factors that release credit constraints to mobility and prices. The trigger may be a shock to house price fundamentals like interest rates, in which case one may expect house prices to react first and the number of transactions and further house price movements to follow. The trigger may also come from credit market conditions (like deregulation or financial innovations) that would have an immediate impact on mobility and sales and only a secondary impact on price. Consequently, it is not possible to say anything in general about the temporal structure. Depending on the underlying shock, Granger causality between price and quantity may run in either direction. Conditional on the shock, however, the theory has clear empirical predictions. ${ }^{4}$

These models are usually formulated as equilibrium models with market-clearing prices. The story is not one of prices being slow to adjust and houses selling quicker or slower than usual during an adjustment period. The flow into the market of new houses for sale and the flow out of the market of houses sold are equally affected. In a modified version of the model, where one allowed for the sales process to take some time, one would expect sales to react first and entry of new houses for sale to come with a lag corresponding to the average time to sale.

Another set of explanations focuses on the nature of search and matching in the housing market. In the model of Berkovec and Goodman (1996) sellers are confronted with randomly arriving potential buyers. Neither party has a complete overview of the market. Sellers and buyers set their reservation prices reflecting their own personal economic situation and their expectations of the reservation prices of the opposite side of the market. ${ }^{5}$ A transaction occurs if the buyer's reservation price exceeds the seller's asking price. Sellers and buyers are assumed to observe transaction prices but otherwise to be uninformed about underlying market conditions. They adjust their perceptions of the market price level gradually based on observed prices until a new stationary equilibrium is reached where prices conform to expectations and flows in and out of the market are equal. As a result, a demand increase (a higher arrival rate of potential buyers in the model) leads to an immediate increase in

\footnotetext{
${ }^{4}$ It also implies that sellers with high loan-to-value ratios should tend to set higher asking prices and have longer times on the market. Genesove and Mayer (1997) find support for this prediction.

${ }^{5}$ A large literature deals with optimal pricing strategies; see e.g. Haurin (1988), Horowitz (1992), Knight, Sirmans and Turnbull (1994), Yavas and Yang (1995), Glower, Haurin and Hendershott (1998), Knight (2002), and Anglin, Rutherford and Springer (2003)
} 
transactions followed by a gradual increase in reservation and transaction prices. Turnover remains above normal during the transition process to the new higher equilibrium price. In a stationary equilibrium, transaction prices adjust such that the number of houses on the market is constant, i.e. the arrival of new sellers exactly matches the number of houses sold. Since market shocks are assumed not to be observable to market participants, the model gives rise to a positive correlation between price change and turnover during the transition process. This property is driven by the assumption that price expectations do not fully reflect current market conditions but adjust mechanically to the difference between last period's price and the price that would be required in order to equate the rate of entry and exit from the market. Once in full equilibrium there is no price-volume correlation.

In a search market, a correlation between price and volume may also reflect variations in liquidity and the quality of matching between buyers and sellers. Many sales and more houses on the market should be associated with higher liquidity in the sense of a shorter time to sale and less price uncertainty. This connection has been analyzed by Krainer (2001) and NovyMarx (2009) in a search market context. Krainer explicitly models the fact that individuals are typically on both sides of the market. The decision to sell and buy is driven by a stochastic process indicating if the household is well matched or not with the particular housing unit it occupies. The value a household derives from a house depends on two factors: an idiosyncratic component and a market fundamentals component that is common to all households. Buyers and sellers follow optimal pricing and search strategies. The higher are market prices, as driven by fundamentals, the higher is the opportunity cost of not being matched and the more eager are buyers and sellers to set reservation prices so as to ensure quick transactions. This leads to the conclusion that sales, liquidity and prices are positively correlated. This conclusion depends crucially on the, realistic, assumption of the absence of a well functioning rental market that households could turn to in order to satisfy their demands for housing. If households could move between owning and renting at no cost, then the opportunity cost of not having found a house to buy and live in would vanish and there would be no correlation between price and liquidity. The matching model of Novy-Marx emphasizes that a demand increase, represented by an inflow of buyers, will increase the match rate between buyers and sellers. This will also have a feedback effect on the ratio of buyers to sellers that further reinforces the initial price impact. 
Another explanation for the price-volume correlation derives from behavioral considerations. A couple of studies have found evidence that homeowners have an aversion to making losses. Genesove and Mayer (2001) and Engelhardt (2003) represent seller behavior by prospect theory implying that the marginal disutility of losses exceeds the marginal utility of gains. If this is so, sellers should be reluctant to setting an asking price below their original purchase price. Both papers find empirical support for this hypothesis. Genesove and Mayer analyze detailed data on condominium sales in Boston and find that owners with nominal losses set higher list prices and accept longer selling times than other sellers. Engelhardt, using nationwide US data, finds that loss aversion has a significant impact on intra-metropolitan mobility. On the other hand, Englehardt does not find evidence of a connection between equity and homeowner mobility, in contrast with theories emphasizing credit constraints.

These three broad approaches are of course not mutually exclusive. The credit constraint story is about the balance between demand and supply in the market and is typically told assuming immediate market clearing, but it could of course be enriched by adding a search process. The loss aversion theory was tested by Genesove and Mayer in a search setting but could also be told in a world of clearing markets where houses with lower reservation prices were simply not entered onto the market.

Most previous empirical studies of the price-volume correlation have been confined to looking at the aggregate number of sales and transactions prices. As a consequence, they have been limited in their ability to discriminate between the different underlying mechanisms. In contrast, our Dutch data include information about both list prices and transaction prices as well as the number of new houses offered for sale and the number of completed sales. This allows us to provide more detail about the dynamics of the housing market adjustment process than in earlier studies. Like Hort (2000) and Andrew and Meen (2003) we focus on the transmission process from news about fundamentals to house prices and transaction volumes. But unlike these and other earlier studies we are able to decompose the variation in the number of houses sold into variations in the number of houses entered onto the market (the rate of entry) and the probability of sale. Further, we can test whether new information first gets incorporated into list prices or sales prices.

The theories presented in the previous Section differ in their empirical implications. The credit constraint view is basically an equilibrium story, where shocks to fundamentals more or 
less simultaneously increase prices and induce more trades. Causality goes from fundamentals to prices and houses bought and sold with feedback effects back to prices. The key empirical prediction is that shocks to fundamentals should have an impact on the entry of new houses onto the market (and on price). The theory has nothing to say about the micro structure of markets, i.e. it does not yield predictions about the rate of sale.

Among the search models, there are two distinct mechanisms. One is an equilibrium story: the more houses there are on the market the higher is liquidity and the easier it should be, ceteris paribus, to find good matches between buyer and seller. This implies that in a more liquid market, with a higher rate of entry of new houses onto the market, the rate of sale should be higher and possibly also prices. This reasoning presumes that the sellers of these houses also appear on the other side of the market as sellers, i.e. it presumes a closed market with no migration. For this reason, it is not straightforward to test the equilibrium search model without auxiliary assumptions about the nature ofshocks.

There is also an imperfect information search mechanism, associated with Berkovec and Goodman (1996). This emphasizes the adjustment process outside of equilibrium. In one version of this theory, buyers demand is affected by shocks to fundamentals but neither buyers nor sellers are fully informed about (or capable to infer) the market consequences of changes in fundamentals. They will adapt their expectations about market equilibrium prices only gradually as a result of observed transaction prices and time on the market. Shocks to fundamentals would have an immediate impact on the reservation prices of buyers but a delayed impact on the reservation prices of sellers. As a result the rate of sale would shoot up immediately but prices would only move gradually. There might also be a secondary impact on the entry of new houses onto the market to the extent that a purchase is followed by a sale.

\section{Prices and quantities in the Dutch housing market}

In this Section we present the data used in our study and displaty some descriptive statistics, thereby sketching the history of the Dutch housing market since the mid-1980s. Our main source is a data base maintained by the Dutch Association of Real Estate Brokers and Real Estate Experts (NVM). NVM organizes the majority of real estate brokers in the Netherlands. Today the organization has more than 4000 members. Together, NVM brokers handle more 
than half of all transactions of owner-occupied homes. The market coverage has been growing over the years, from 25-30 percent in the 1980s to 55-60 percent today. Membership is unevenly distributed across the country. In Amsterdam the NVM market share is now 75 percent, substantially higher than in more rural regions.

Member brokers are required to report to NVM all dwellings (apartments and one-family houses) offered for sale. Information given includes the initial asking price and the date the house was put on the market as well as the date and price of sale. ${ }^{6}$ For an unsold house the date of withdrawal from the market is recorded. The records also include the exact address, an exhaustive list of physical characteristics and subjective assessments of the standard of the dwelling.

\section{Prices}

Based on the NVM data we compute two hedonic nationwide price index series: one for the initial list price and one for the final transaction price. The original data base contains 3,074,368 observations on dwellings offered for sale during the period January 1985 December 2007. After deletion of data with missing observations and some outliers, we make use of 1,950,666 observations for the list price regressions and 1,890,633 observations for the sales price regressions. The index estimates are based on log-linear hedonic regressions performed year-by-year using monthly dummies. Geographical price variation is controlled for by 76 regional dummy variables. Details on the index estimation are given in Appendix 1 .

The sales price regression has somewhat better fit in every year, although the regression coefficients are quite similar for the two regressions. The average $\mathrm{R}^{2}$-value of the sales price regressions is 0.813 compared to 0.799 for the list price regressions. In general, there seems to be more noise in prices in times of price increase. Both hedonic equations are more successful in cold than in hot markets. In 1994-96, when prices were stagnating, the average $\mathrm{R}^{2}$ was 0.826 for the sales price equation (and 0.818 for the list price equation) compared with the hot years of 1999-2001 with an average $\mathrm{R}^{2}$ of $0.806(0.777)$.

\footnotetext{
${ }^{6}$ There is also some information about intermediate asking prices. This information appears to be incomplete for part of the sample period, however, and it is not used in this paper. De Wit and van der Klaauw (2009) analyze the process of list price revision.
} 
We link the within-year index series using the mean characteristics of all transacted dwellings during the year and form Laspeyres price indexes. The results are depicted in Figure 3. Our data cover a period when Dutch prices were more or less continuously increasing, almost three-fold from 1985 to 2007. This relatively smooth growth is in contrast to many other markets - notably UK and the Scandinavian countries - that saw prices falling in nominal terms in the early 1990s, and others - including the US, UK and Spain - that have experienced sharp price reductions in recent years. Part of the reason for the difference may be the severe housing market crisis in the Netherlands in the early 1980s, when prices fell by a third between 1978 and 1982. As a result the Dutch housing price level was quite depressed in 1985 when our data start, most likely below its long-run equilibrium level. Some of the subsequent price rise may hence be seen as a catch-up effect. When prices fell dramatically in other countries in the early 1990s they were only dropping slightly in the Netherlands. Subsequently, prices shot up sharply again from the middle of the decade with the rate of yearly price growth gradually increasing to around 7 percent in 1998. Prices stagnate again after 2000, but continue to increase slightly until the end of our data. The price increase went on past the sample until reaching a peak in the middle of 2008 , followed by a modest price fall by 4 percent until the second quarter of 2009 (according to the price index published by the Central Bureau of Statistics).

\section{List prices and sales prices}

In the Dutch market, the list price represents a commitment from the seller to sell at the posted price. Apparently this is not strictly binding and the data set has some observations where the sales price exceeds the asking price. The great majority of dwellings, however, were sold below ( 86.1 percent of all sales) or exactly at (9.6 percent) the list price. Only 4.3 percent of all sales prices exceed the list price. Prices in excess of the list price were somewhat more common in the late 1990s when prices were increasing generally. The two price indexes follow each other rather closely as seen in Figure 3. The discount of transaction price relative to list price - calculated as the log difference between the transaction price index for houses that were sold in month $t$ and the list price index for houses entered on the market in month $t-2$ (two months being the mean lag from entry to sale) - is shown in Figure 4. The discount has fluctuated between 5.5 and 13 percent. The variation appears to reflect a combination of trend and cyclical developments. There are local peaks corresponding to the periods of stagnating prices in the early 1990s and early 2000s as well as a low mark in the boom market of the late 1990s when the rate of price increase was at its highest. At the same 
time there is a trendwise development with a much lower discount in recent years than at the beginning of the sample period, perhaps reflecting changing market institutions.

\section{Houses for sale and houses sold}

In calculating time series of houses sold and houses on the market, we have to account for the fact that the NVM market share has increased during the sample period. Thus, new houses entered into the data base partly reflect new brokers entering the NVM reporting system. We have corrected for this based on information on the total number of sales obtained from the Dutch Land Registry (the Kadaster). The correction is based on the presumption that sales through NVM brokers are representative for all sales, i.e. that there are no systematic differences between NVM brokers and other brokers. Details of the correction are described in Appendix 2.

Figure 5 depicts the rate of sale, defined as the number of houses sold during one month divided by the number of houses on the market in the beginning of that month. The rate of sale increased gradually, interrupted by a minor decrease in the mid 1990s, from below 20 percent in the 1980 s to close to 50 percent when the rate of price change peaked in late 1998 . In that hot market, many houses literally sold immediately when they were entered onto the market. Subsequently the market calmed down with stagnating prices, and the rate of sale fell back to below 20 percent after 2002. Overall, as we saw from Figure 2, the correlation between the rate of sale and price increases is quite strong.

Whereas the rate of sale is a natural measure of market liquidity it does not tell the whole story about the total number of houses sold. By definition, the number of sales equals the rate of sale times the number of houses on the market, and the percentage change in number of sales is, hence, approximately equal to the sum of the rates of change of the rate of sale and the number of houses on the market. Figure 6 illustrates this decomposition of (the 12-month average of) the change in the number of sales. The change in the number of sales and the rate of sale follow each other very closely with a correlation coefficient as high as 0.96 . The correlation between the change in sales and the change in houses for sale, on the other hand, is only 0.34 . Variations in sales seem to be driven by variations in the match rate between buyers and sellers rather than by variations in the flows of houses in and out of the market. 
The change in the inventory of houses for sale is the net result of three gross flows in and out of the market: new houses for sale, houses sold, and withdrawals of unsold houses from the market. Expressing these flows as fractions of the number of houses on the market, it holds identically that the rate of change of number of dwellings on the market $\equiv$ the rate of entry the rate of sales - the rate of withdrawal. These flows are depicted in Figure 7. The first thing to note is the magnitude of the gross flows relative to the net change in the number of houses on the market. In any month, the new houses for sale entered onto the market correspond to between 10 and 50 percent of all houses on the market, but at the same time almost as many houses are sold. As a result, the number of houses on the market rarely changes by more than 1-2 percent up or down in a single month. The strong correlation between the gross flows is natural since most transactions are related to household moves from one house to another. ${ }^{7}$ Withdrawals, in contrast, play a minor role for the development of the stock; in any month only between 3 and 5 percent are withdrawn from the market ${ }^{8}$. Over time, however, even small imbalances between the flows can add up to significant changes in the inventory of houses on the market. In fact, from 1985 to 1996 the inventory decreased by as much as two thirds from 180,000 to 60,000 . Starting around 1993 gross flows increased sharply. The rates of entry and sale both doubled from 20 to 40 percent. At the same time the difference between the rate of entry and the rate of sale again got larger and the number of houses more than doubled to reach 150,000 in 2005. At the end of the sample period in 2007 the inventory was again down below 100,000. In the recent housing bust, sales have fallen by almost $50 \%$ from mid 2007 to mid 2009.

For our econometric analysis we would like to identify exogenous shocks to the entry of new houses as one of the drivers of prices. From that perspective, it is preferable to define the entry rate as the number of new houses for sale divided by the total stock of houses in the economy (rather than, as in Figure 7, divided by the number of houses for sale on the market, which is endogenous). The rate of entry defined in that manner is depicted in Figure 8. We see that generally between 0.3 and 0.4 percent of the total housing stock is entered onto the market in every month. There are strong seasonal variations with troughs in December and peaks in March. Beyond that, there is some low-frequency variation with a gradual decrease in the rate of entry until the mid 1990s, a gradual increase until the turn of the millennium and

\footnotetext{
${ }^{7}$ Mobility within the owner-occupied market is far from the whole story, however. For US data Wheaton and Lee (2009) find that rent-to-own and own-to-rent flows are each as large as own-to-own flows.

${ }^{8}$ De Wit (2009) studies the duration-dependence of the hazard rates of sale and withdrawal.
} 
a slight decrease thereafter. The increase in the entry rate between 1995 and 2000 roughly coincides with the increase in the rate of price change during the same period. There is a positive correlation between the rate of entry and price changes, but not at all as strong as between the rate of sale and price changes.

\section{Fundamentals}

The key issue of our analysis is understanding the transmission process from underlying shocks to house price fundamentals onto prices and sales. Fundamentals should include the main determinants of demand and supply. Other studies of Dutch housing prices, including Boelhouwer et al. (2001), Kranendonk and Verbruggen (2008), and Francke et al. (2009), all represent the demand side by the real interest rate and an income variable, both of which are strongly significant in determining long-run house prices. Kranendonk and Verbruggen also include net financial wealth and a measure of supply. As we are interested in capturing highfrequency (monthly) price and quantity movements, we are somewhat limited in our access to data. In particular, monthly income data are not available. Instead we include unemployment, measured by the three-month moving average of the open rate of unemployment (source: Statistics Netherlands, CBS). This series is depicted in Figure 9. It combines a falling longrun trend from 10 to 2 percent from the beginning to the end of the sample period with shortterm cycles with peaks around 1993 and 2004.

Interest is measured by the monthly average across all new five-year fixed rate residential mortgages (source: CBS). We convert this into a real interest rate by deducting a measure of the expected rate of inflation, constructed from an autoregressive moving average process, i.e. an ARMA $(7,7)$ model with monthly dummies. We make 60 -month ahead forecasts of the

inflation rate. We compound and annualize these forecasts and deduct them from the nominal interest rate. The resulting series is depicted in Figure 10 along with the original nominal interest rate. The inflation correction corresponds, by and large, to a parallel downward shift by around 2 per cent, reflecting the fact that inflation fluctuations have been modest. The general pattern of the interest development is somewhat similar to that of unemployment: a falling trend, from 6 to 2 percent during the sample period, combined with cyclical peaks. But the correlation between unemployment and interest is far from perfect. In particular, the years after 2000 exhibit falling interest rates along with increases in unemployment. 
As we will see from the econometric model, both interest and unemployment are significant in explaining house prices in the long run. Shocks to the unemployment rate, however, seem to have little impact on the short-term dynamics of the model. As an alternative we tried using a broader business cycle indicator taken from den Reijer (2006), but with similar results.

\section{Econometric modelling}

The correlation between price and sales reflects both short-run fluctuations and long-run trends. We need an econometric framework that allows us to model long-run determinants of the underlying equilibrium as well as short-run deviations from this equilibrium. The natural vehicle for such analysis is a vector error-correction model (VECM), where the dynamics are given by the combination of current and past shocks and the gradual adjustment towards equilibrium. This model presumes that the variables included are non-stationary but cointegrated, meaning that linear combinations of the variables are stationary. These linear combinations can be interpreted as equilibrium relations. A VECM can be written as

$$
\Delta y_{t}=\mu+\alpha\left[\beta^{\prime} \quad \eta\right]\left[\begin{array}{c}
y_{t-1} \\
t-1
\end{array}\right]+\sum_{i=1}^{p-1} \Gamma_{i} \Delta y_{t-i}+\Phi D_{t}+u_{t},
$$

where $y$ is a $(K x l)$ variable vector. In our case $K=6$ and the vector $y$ consists of the variables described in the previous Section: two prices - the real list price $l p$ and the real transaction price $t p$ (both in logs) ; two quantity variables - the rate of entry $e$ (defined as the number of new houses for sale divided by the total stock of houses) and the rate of sale $s$ (defined as the number of houses sold divided by the number of houses for sale on the market); two fundamentals - unemployment $u$ and the real mortgage interest rate $i$ (both in logs). ${ }^{9}$ The $(K x l)$ vector $\mu$ consists of constants, and the $(K x r)$ matrices $\alpha$ and $\beta$ are the loading and the cointegration matrix, respectively, where $r$ is the number of cointegrating relations and $\beta^{\prime} y$ are the cointegrating relations. The vector $\eta$ is a time trend to allow for the influence of omitted variables. The $\Gamma_{i}$ matrices contain the short-run parameters. The matrices $D$ consist of centered seasonal dummies and the matrix $\Phi$ is the corresponding coefficient matrix.

\footnotetext{
${ }^{9}$ We have also estimated a seven-variable VEC-model also including the rate of withdrawal. This variable, however, was generally insignificant and did not affect other properties of the model. Hence, we are only reporting results from the six-variable VEC-model.
} 
The data set covers all NVM transactions from January 1985 to December 2007. For the econometric analysis we exclude all observations for 1985, since it is not possible to construct a reliable measure of the inventory of houses on the market for this year. Such a measure would have to be computed based on reported market flows in 1984 (and possibly earlier) when reporting was incomplete. Further, we also exclude the last six months of 2007. The reason is that brokers only report to NVM once an entire spell from entry to sale or withdrawal is completed. This implies that observations for the last few months of the data base would have an over-representation of short spells. To avoid having our results contaminated by this we exclude observations at the end of the sample. ${ }^{10}$

To specify the model we first test the variables for stationarity. Results are shown in Table 1. We are unable to reject the null hypothesis of non-stationarity for five of our six variables: the two prices, interest, unemployment and the rate of sale. All these variables are stationary in differences. For the rate of entry $e$, on the other hand, we reject non-stationarity at the 2 per cent level. It may seem somewhat inconsistent to treat the rate of sale as an I(1) variable and the rate of entry as $\mathrm{I}(0)$. But since the entry rate primarily reflects mobility and is normalized by the stock of houses, whereas the sales rate reflects market liquidity and is normalized by the number of houses on the market, there is nothing inconsistent in having different orders of integration. It should be noted, however, that it implies that there are no long-run linkages between the rate of entry and the other variables in the model.

We expect the non-stationary variables to be linked together in the long run by equilibrium conditions. Table 2 reports Johansen (1996) trace tests for the number of cointegrating vectors. In the tests we exclude the stationary variable $e$. The null hypothesis of two vectors is rejected in favor of three or more vectors $(p$-value $=.03)$, but the null of three vectors is not rejected $(\mathrm{p}$-value $=.86)$. The test reported in the table is based on 3 lags, which is the optimal lag length in the model (including the rate of entry) according to different criteria (Akaike Info Criterion, Final Prediction Error and Hannan-Quinn Criterion). The test results for the number of cointegrating vectors are robust to the choice of lags. Consequently, we base our VEC-model on three cointegrating vectors.

\footnotetext{
${ }^{10}$ This exclusion has some impact on the estimates. In particular, the restrictions we put on the cointegrating vectors would be rejected if we used the full data set up to 2007:12.
} 
In estimating the model, we impose restrictions on the cointegrating vectors that allow us to interpret the vectors as economically meaningful equilibrium conditions. Specifically, we estimate three exactly identified vectors based on the following assumptions:

- The transaction price is determined by the fundamentals: there is a cointegrating relation between $t p, u$ and $i$.

- The ratio of list price to transaction price is determined by the fundamentals: there is a cointegrating relation between $t p, l p, i$ and $u$ with the coefficients for $t p$ and $l p$ restricted to plus and minus one.

- The transaction price is related to the rate of sale and the interest rate: there is a cointegrating relation between $t p, s$ and $i$.

Imposing these restrictions, we estimate the model by the maximum-likelihood approach proposed by Johansen. ${ }^{11}$ All equations include monthly dummies and a linear trend. The model also includes the rate of entry, which is treated as a stationary variable. Table 3 provides the estimation results for $\alpha, \beta$ and residual standard errors and cross correlations, using the effective sample from January 1986 to June 2007.

We think of the fundamentals as the basic driving forces and the price and quantity variables as indicators of the state of the market. The distinction between fundamental determinants and endogenous market responses is not clear-cut, however. The model allows analyzing the impact of shocks to all six variables, including the market indicators. Shocks to the price and quantity variables represent market impulses that are not due to interest and unemployment shocks. The rates of sale and entry are affected by mobility. An increase in emigration or in the transition from owning to renting would put more houses on the market, i.e. be reflected in a shock to the rate of entry. An increase in immigration or in the transition from renting to owning would, all else equal, mean that houses sold more easily, i.e. show up as a shock to the rate of sale. A pure mobility shock - e.g. due to lower transaction costs - would mean a more or less simultaneous shock to both sides of the market and affect both the rate of entry and the rate of sale. If households typically would buy a new house before selling their old house, as is often assumed in search models of the housing market following Wheaton (1990),

\footnotetext{
${ }^{11}$ The estimation is performed using CATS for RATS version 7.10. The stationary variable $e$ is included in the vector $y$. For this variable we have a column in matrix $\beta$ with a unit in one position and zeros elsewhere; see Lütkepohl (2006) for more details.
} 
then an intra-market mobility shock would affect the rate of sale immediately and the rate of entry with a lag of a couple of months.

How are fundamental shocks transmitted into market indicators? How do prices and quantities react to shocks? How important are different shocks in explaining the variation in prices and quantities? The answers according to the estimated model can be illustrated by means of impulse response functions, showing the impact of one-standard-deviation shocks. Variance decompositions split the variance in forecast errors into the contributions from the different shocks. To allow meaningful interpretation, the shocks are orthogonalized so as to be uncorrelated with each other. The orthogonalization is based on the assumption that the simultaneous interaction between the variables has a recursive structure, i.e. a Choleski decomposition. Since results may be sensitive to the recursive ordering we have calculated impulse responses and variance decompositions for the following four orderings

1. $u, i, e, s, l p, t p$

2. $u, i, e, s, t p, l p$

3. $u, i, s, e, l p, t p$

4. $u, i, l p, t p, e, s$.

In all orderings the macroeconomic variables $u$ and $i$ go first, as our main focus is on understanding how shocks to these are transmitted into prices and quantities. In cases 1-3 they are followed by the quantities (entry and sale), with the prices coming last. Cases 2 and 3 differ from case 1 by reversing the ordering between the list price and the sales price (case 2) and between the rate of entry and the rate of sale (case 3). In case 4, finally, the ordering between the block of prices and the block of quantities is reversed.

\section{Results}

Details of the estimated model are given in Table 3. Let us first look at the equilibrium properties represented by the cointegrating relations and then go on to study the dynamics of the model.

\section{The cointegrating relations}

Imposing exactly identified coefficient restrictions as discussed in the previous Section, we get the following estimates of the cointegrating vectors. 


$$
\begin{aligned}
& t p=-0.232 u-0.264 i+0.002 t \\
& l p-t p=-0.0011 u-0.017 i-0.0002 t \\
& t p=0.331 i-2.150 s+0.006 t
\end{aligned}
$$

The first equation can be interpreted as a reduced form price equation. The equilibrium elasticities of price with respect to unemployment and interest are -0.23 and -0.26 , respectively. There is a positive price trend of 0.2 per cent per month reflecting the influence of income, demographics and other factors not present in the model. The models of Krankendonk and Verbruggen (2005) and Francke et al. (2009) both find income elasticities on the order of unity. Combined with a period of income rising with a couple of percent per year, this translates into a positive price trend comparable to the one we have estimated. The interest elasticity is higher than the -0.086 estimated by Francke et al in their one-equation error-correction model.

The second equation gives the equilibrium elasticities of the premium of list price over sales price as a function of interest and unemployment. Both elasticities are negative; the higher is the interest rate (the cost of waiting) and the higher is unemployment the more eager are households to sell quickly and the lower is the list price relative to the sales price. The elasticities may seem quite small, 1.1 and 1.7 per cent, respectively. But remember that these are elasticities of the ratio of list price to sales price (not of the premium). To get a sense of the magnitudes consider the impact of the real interest rate falling from its peak value of 7.5 per cent (recorded in 1990) to the lowest value of 1.2 percent (in 2005). A change of this magnitude would cause the ratio of list price to sales price to fall by 3.1 percent. This effect should be related to the fact that the list-to-sales-price ratio has fluctuated between 1.057 and 1.024 , i.e. a fall in this ratio of 3.1 percent is equivalent to a fall in the list price premium from its maximum to its minimum observed value.

Finally, according to the third equation, an increase in the rate of sale by one percentage point is accompanied by a decrease in the sales price by two percent. Despite the fact that monthly observations of the price changes and the rate of sale are positively correlated, we find a negative long-run relation between these variables. This runs counter to the idea that the positive short-run correlation reflects a liquidity premium. It should be pointed out, however, 
that caution is needed in giving structural interpretations to the cointegrating equations. Indeed, any linear combination of two cointegrating vectors is also a cointegrating vector.

The residuals from the cointegrating relations are displayed in Figures 11a-c. In the latter half of the 1990s, when interest and unemployment rates both were falling, the residual of the first equation went from positive to negative. Interpreting this as deviations from the fundamental market price, this indicates that house prices went from over- to under-valuation. As prices continued to increase despite interest rates picking up from 1999, under-valuation quickly turned into over-valuation. After that the residual has been quite volatile. Following several years of stagnating house prices after 2000, our model indicates that Dutch house prices were in fact under-valued in relation to fundamentals by 7 percent in 2007 . The residuals from the second equation indicate that the list price premium was below its fundamental value in the period of increasing sales prices in the late 1990s, perhaps reflecting that prices were increasing faster than expected when list prices were set. Conversely, there was a large premium, i.e. sales prices were low relative to list prices, when the market was stagnating in the early 1990 s and after 2000.

\section{Impulse responses}

The dynamic properties of the model are illustrated by means of impulse response functions and variance decompositions. The impulse responses show the predicted dynamic paths following on a one-standard-deviation shock, orthogonalized according to either of the recursive schemes stated above. By and large the results are insensitive to the ordering of shocks and we will focus on the first ordering. As a further robustness check, we have also computed, for the first ordering, impulse response functions based on a model with no restrictions on the cointegrating vectors. With one exception (the impact of the rate of entry on price), the results are similar to the results based on the restricted long-run model.

The entire sets of impulse responses for the different orderings are reported in Appendix 3 with 95-percent confidence intervals computed using the method proposed by Sims and Zha (1999). Here we will focus on discussing the most important impulse responses. Among the two fundamentals we get the clearest results for interest shocks. A one-standard-deviation interest shock leads to a permanent increase of the mortgage rate by 4 per cent (equal to 15 basis points at sample mean). The responses of the transaction price and the rate of sale are depicted in Figures $12 \mathrm{a}$ and $\mathrm{b}$. The trajectory for the list price is almost indistinguishable 
from that of the transaction price, and there is no indication of the list price leading or lagging the sales price. In other words, new information seems to be incorporated into both prices simultaneously. Comparing the price and quantity responses, we see a clear contrast. While the impacts on prices are gradual but lasting, the impact on sales is immediate but temporary. The rate of sales falls by 0.6 per cent already within two months and remains at about that level for around a year before reverting back to the pre-shock level. During this period of lower market activity prices gradually adjust towards the new equilibrium. It takes three months until the price decrease is large enough to be statistically significant. After six months the price is down by 0.5 percent and it continues to decrease for two years until reaching a new equilibrium level about one percent below the starting position. This pattern with sales reacting before price confirms previous empirical results of Hort (2000) and Andrew and Meen (2003) and fits well with the disequilibrium search story. The impact on the rate of entry is negative (in line with the credit constraint story) but very small and far from significant.

The unemployment shock has essentially no impact on any variable of interest. This may seem surprising since unemployment enters with a negative sign into the first cointegrating relation. It turns out, however, that an unemployment shock has a negative impact on the interest rate perhaps because it triggers an expansionary monetary policy. The net effect of these two countervailing influences is a negligible impact on prices as well as on the rate of sales.

Shocks to the rates of entry and sale are by definition shocks to the supply of houses on the market - positive for an entry shock and negative for a sales shock. They may reflect different underlying shocks, e.g. to demographics, tenure choice or mobility within and across markets. A sales shock may also be a shock to the matching process between buyers and sellers. Viewing the shocks as supply shocks, one would expect more entry to have a negative price impact and more sales to have a positive impact. First, looking at the own-responses, it is seen that both shocks are relatively long-lived; the responses remain significantly positive for around one year (the rate of entry) and almost two years (the rate of sales). Both shocks affect prices in the expected direction. Increasing the rate of sales by one standard deviation leads to a gradual increase in price by around 0.7 per cent, with the full effect reached after two years by which time the rate of sale is back at its original level. The magnitude of the impact of an entry shock is about the same, with opposite sign. This is consistent with entry shocks 
reflecting either emigration or moves from ownership to renting and sales shocks reflecting either immigration or moves from renting to owning.

Changes in the rate of sale may also reflect mobility within the owner-occupied sector. If that were the case there would be cross effects between the rate of sale and the rate of entry. If households typically purchase a new house before putting their current dwelling on the market, then a sales shock should have a positive cross-effect on the rate entry with a lag of a couple of months. This effect, however, is negative in the very short run and essentially zero after a few months.

The rates of sale and entry may also be related if there are strong thick-market effects. Then an entry of more houses onto the market would facilitate matching and lead to an increase in the rate of sale. In the model a shock to the rate of entry does have such a positive cross effect, but it only lasts one month. After a few months it turns negative, though not quite significant, despite the fact that the impact on the rate of entry stays significantly positive for about a year.

Price shocks, finally, may be interpreted as demand (or supply) shocks other than those related to interest and unemployment and those directly affecting sales and entry. Shocks to transaction prices have little or no impact on anything, including transaction prices themselves after a couple of months. Shocks to list prices, on the other hand, have a lasting effect and spread almost immediately onto sales prices with a lag of a couple of months. This suggests that information about some permanent changes in market conditions first gets incorporated into list prices and then affects sales prices with a lag corresponding to the normal time on the market. This pattern contrasts with the reaction to other shocks, which affect both prices equally. One interpretation is that list price shocks reflect local information that is not dispersed as quickly to the entire market. Finally, we note that price shocks have little or no impact on the rates of sale and entry, i.e. there is no indication of the dynamic feedback associated with the credit constraint story.

\section{Variance decompositions}

The impulse response functions help us to relate the sales-price correlation to the underlying shocks. They indicate that the correlation could be driven by interest shocks as well as shocks to the rate of sale, both of which trigger price and sales to move in the same direction during 
the transition towards equilibrium. Price and entry shocks, on the other hand, do not give rise to such a positive correlation. The question is which of these shocks are most important. Figures 13 and 14 decompose the variations of the forecast error of the sales price and the rate of sale at different horizons into the different shocks. For the sales price, most of the variance over short horizons is due to price shocks, with list price shocks being more important than shocks to transaction prices already from three months and onwards. This confirms the conclusion that there is important information content in list prices. At a year's horizon and longer most of the sales price variance is accounted for by other shocks than price shocks. Interest shocks and entry shocks are somewhat more important than sales shocks, accounting for 32,33 and 22 percent respectively after five years. The variance decomposition of the list price looks almost identical to that of the transaction price at horizons longer than a year. The variance decomposition for the rate of sale is illustrated in Figure 14. Here own shocks to the rate of sale remain dominant up to three years and continue to account for as much as 29 percent even after five years. Mortgage shocks account for almost as much ( 28 percent after five years), while entry shocks only account for 12 percent after five years.

\section{Understanding the price-quantity correlation}

We are now in a position to explain the sources of the correlation between price and quantity in the Dutch housing market. Recall that this comovement mainly stems from a strong correlation between variations in price and the rate of sale, whereas the correlation between sales and the rate of entry is low. This is prima facie evidence that the price-quantity correlation reflects aspects of the price formation and micro structure of housing markets rather than simply changes in the balance between supply and demand. Based on the estimated VEC-model we may draw sharper conclusions. If the dynamics of price and quantity were driven by variations in the tightness of credit constraints, then we would expect to see shocks to fundamentals affecting prices immediately and having a secondary impact on the rate of entry of new houses for sale. Since the sellers of houses would also appear as buyers (with some lag) we would not expect to see much impact on the rate of sale. This is the opposite of what our estimated impulse response functions indicate: an interest shock has a gradually increasing effect on price, an immediate but temporary effect on sales and little effect on entry. We conclude that the credit constraint story does not explain the correlation between price and quantity observed in the Netherlands. 
The Dutch evidence is much more consistent with a story of a gradual adjustment of expectations to new information about fundamentals. If buyers and sellers did not fully account for the impact of a shock to fundamentals on market prices, then one would expect to see a gradual price change, but an immediate change in the rate of sale. This is what the impulse response functions indicate. This is also in line with the findings of the studies of Hort (2000), which also looks at interest rate shocks, and Andrew and Meen (2003), which looks at a more general representation of price fundamentals. Both of these papers are limited to studying total sales, however, and do not distinguish between the rates of sale and entry. In this respect, our paper provides sharper evidence about the underlying mechanism.

A number of papers have developed equilibrium search models of the housing market. A common theme in these models is that thicker and more liquid markets are associated with higher prices and a higher rate of sale (shorter time on the market). This would imply that shocks to the rate of entry, bringing more houses onto the market, would lead to higher prices and a higher rate of sale. We find just the opposite. This should not be taken as strong evidence against the equilibrium search models as they are developed for closed housing markets, where anybody who offers his house for sale also appears on the other side of the market looking for a house to buy. A reasonable interpretation of our model is that a shock to the rate of entry largely is a supply shock reflecting moves into or out of the Dutch ownership market, due to migration or switches between owning and renting.

We believe that our results tell a consistent story, but they are of course limited to a particular housing market and a particular time period. Compared to many other markets, the Dutch housing market was relatively balanced throughout the entire period. In particular, there was no period of falling nominal prices, a situation where the credit constraint story may be most relevant. Further, the Dutch credit market offers easier access to mortgage borrowing than most other credit markets. For both these reasons similar studies for other countries and other time periods would be needed before drawing more general conclusions. 


$\begin{array}{llllll}u & i & e & S & l p & t p\end{array}$

$\begin{array}{lllllll}\text { Test statistic } & -1.77 & -2.50 & -3.87 & -1.19 & -0.54 & -0.36\end{array}$

Intercept and linear trend included. Monthly dummies included for all variables except the interest rate. Two lagged differences. $n=258$. Critical values: $1 \%=3.96,5 \%=3.43,10 \%=3.13$. See Said and Dickey (1984).

Table 2: Johansen Trace Test

\begin{tabular}{crr} 
Rank & $L R$ & $p$-value \\
& & \\
0 & 184.38 & 0.0000 \\
1 & 91.53 & 0.0000 \\
2 & 44.43 & 0.0332 \\
3 & 11.26 & 0.8554 \\
4 & 4.91 & 0.6159 \\
5 & 184.38 & 0.0000 \\
\hline
\end{tabular}

LR denotes the log likelihood ratio of the null hypothesis indicated by the rank number against the alternative of a larger rank. Model (1) with $p=3 . n=258$. See Johansen (1996). 
Table 3: The estimated VECM

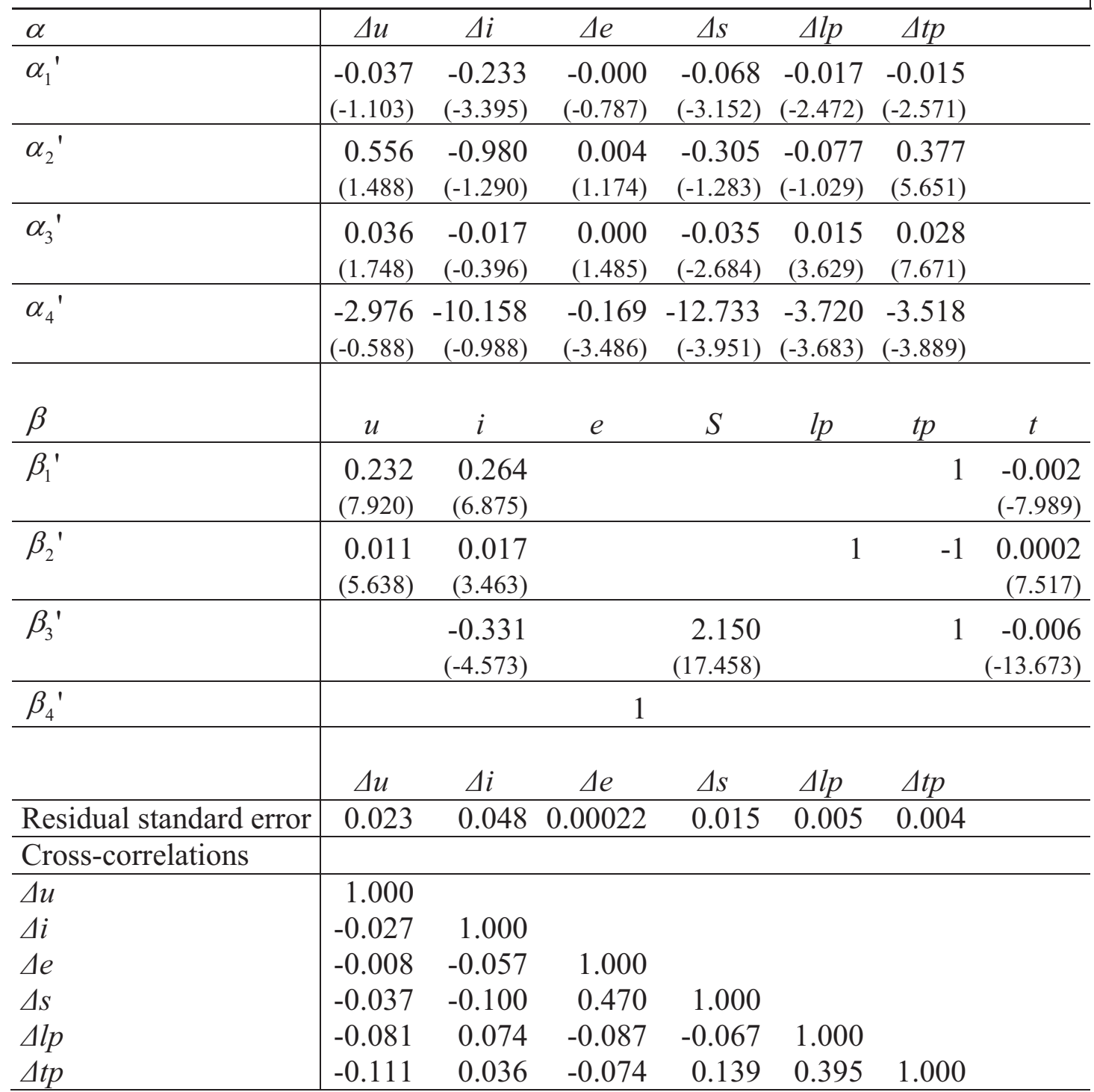

The effective sample is from January 1986 to June 2007. 258 months. The number of lags $p$ is 3 . The identification restrictions are elements of $\beta$ being -1, 0 and 1. Estimates of $\mu, \Gamma_{i}$ and $\Phi$ are not included. 
Figure 1: Number of dwellings sold and the rate of real price change

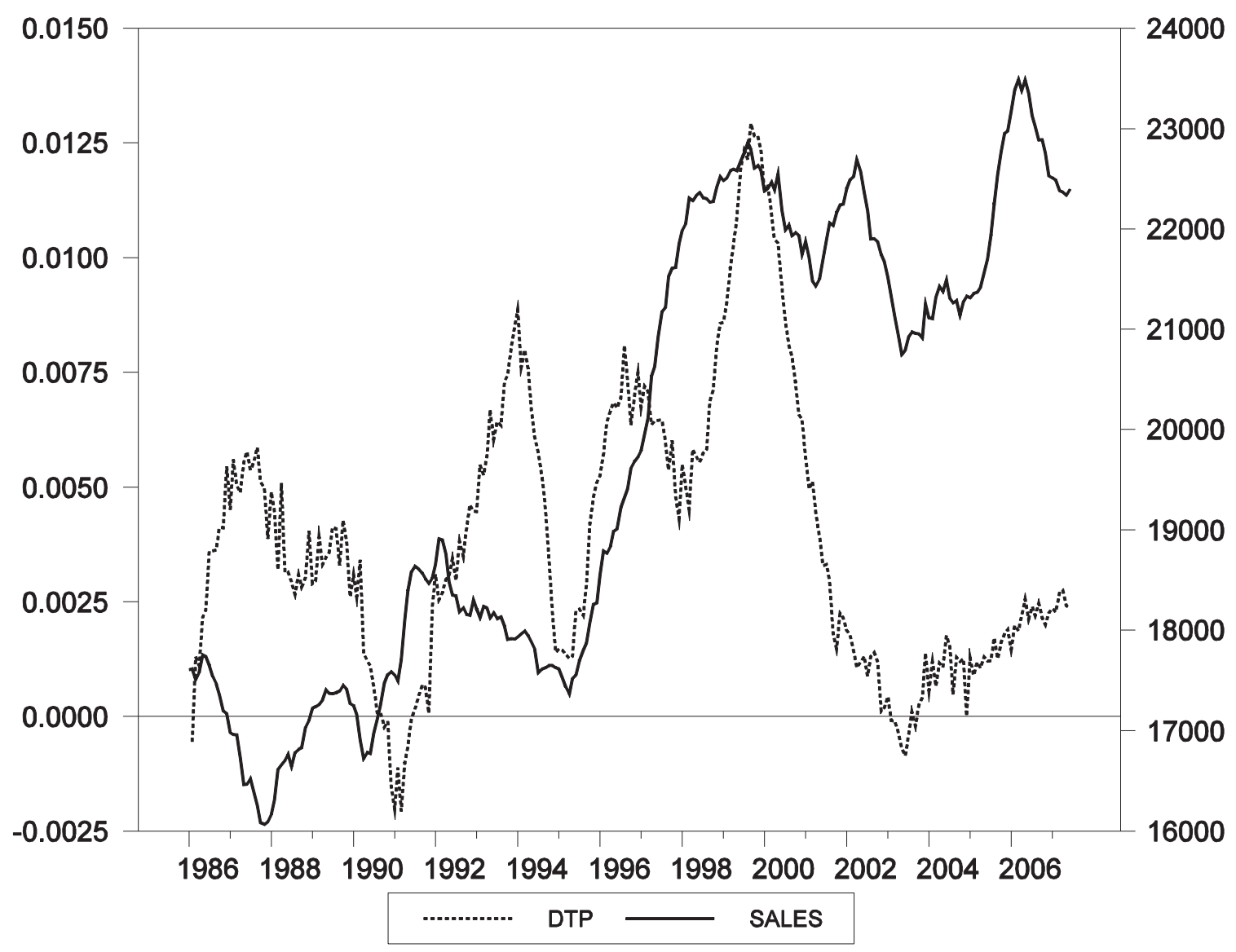

DTP is the rate of price change expressed as the 12 month average of the monthly change in the transaction price index. Sales is the 12 month average of the number of sold houses (where the numbers of sold houses are corrected for the NVM market share). 
Figure 2: Percentage transaction price change (12 month moving average) and rate of sale

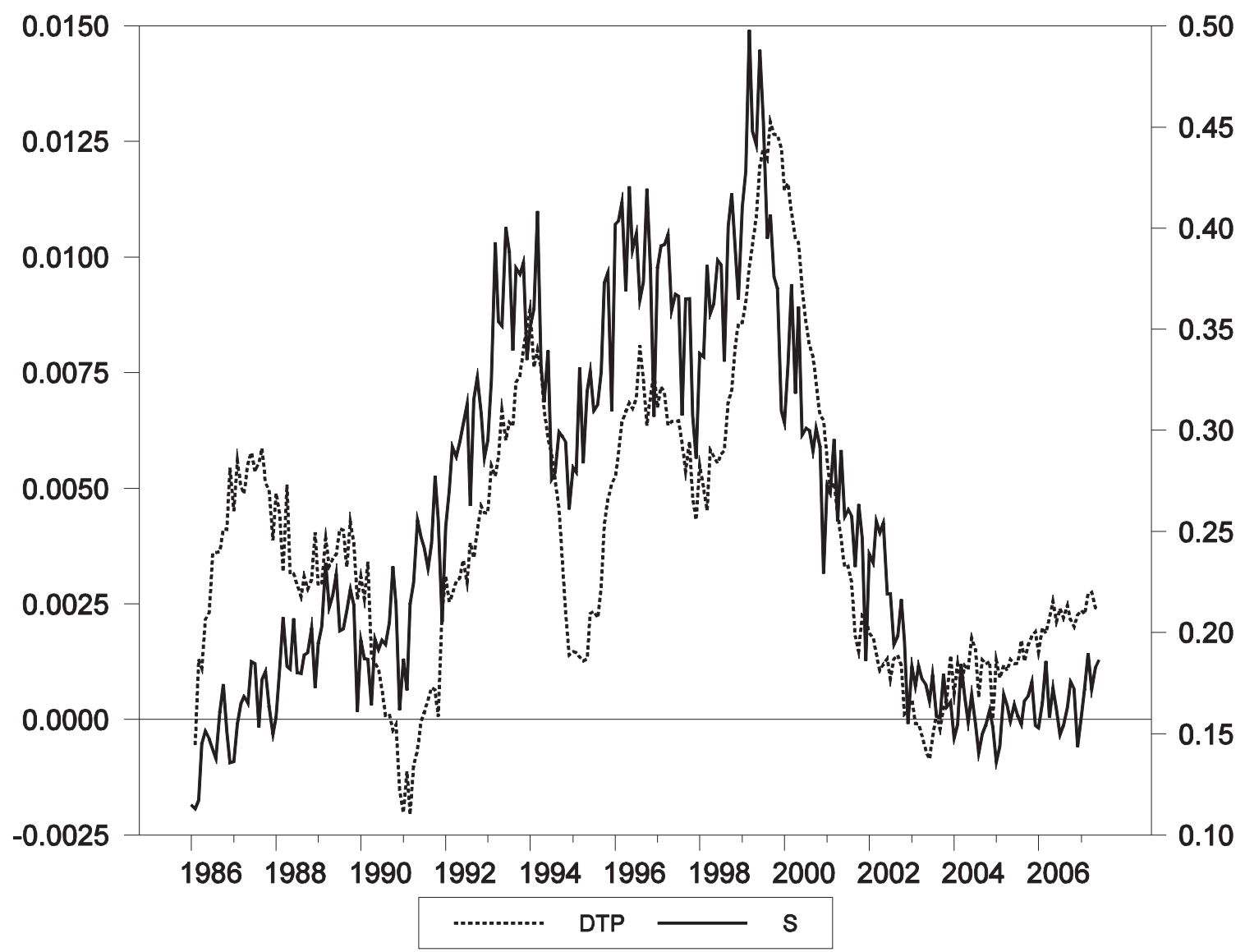

DTP is the rate of price change expressed as the 12 month average of the monthly change in the transaction price index. $\mathrm{S}$ is the rate of sale expressed as the number of houses sold in the current month divided by the number of houses on the market at the start of the month. 
Figure 3: Indexes for sales price and list price, CPI deflated, logs

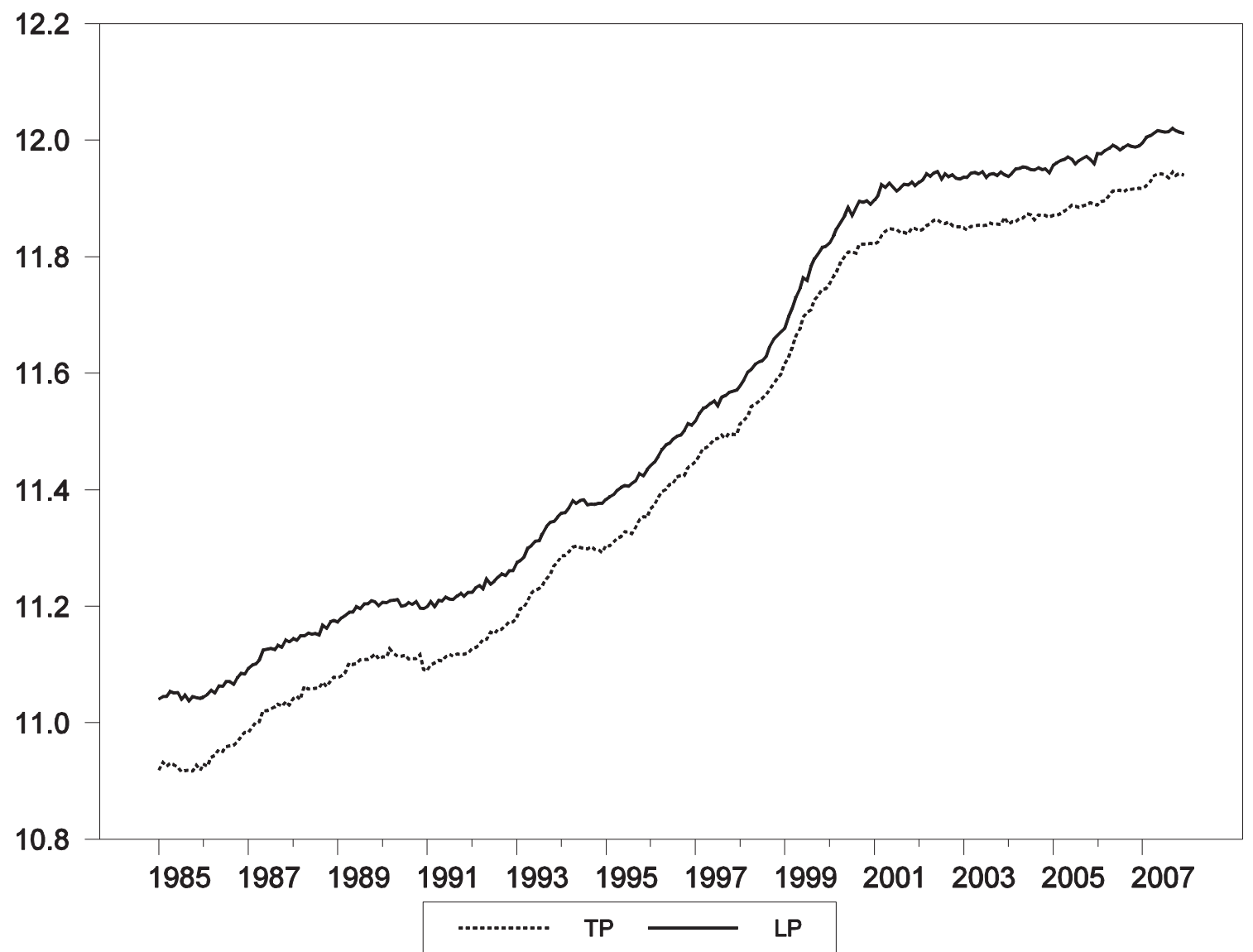

TP is the transaction price index and LP is the list price index. Both indices are CPI deflated and in logs. 
Figure 4. Discount of sales price relative to list price (log difference)

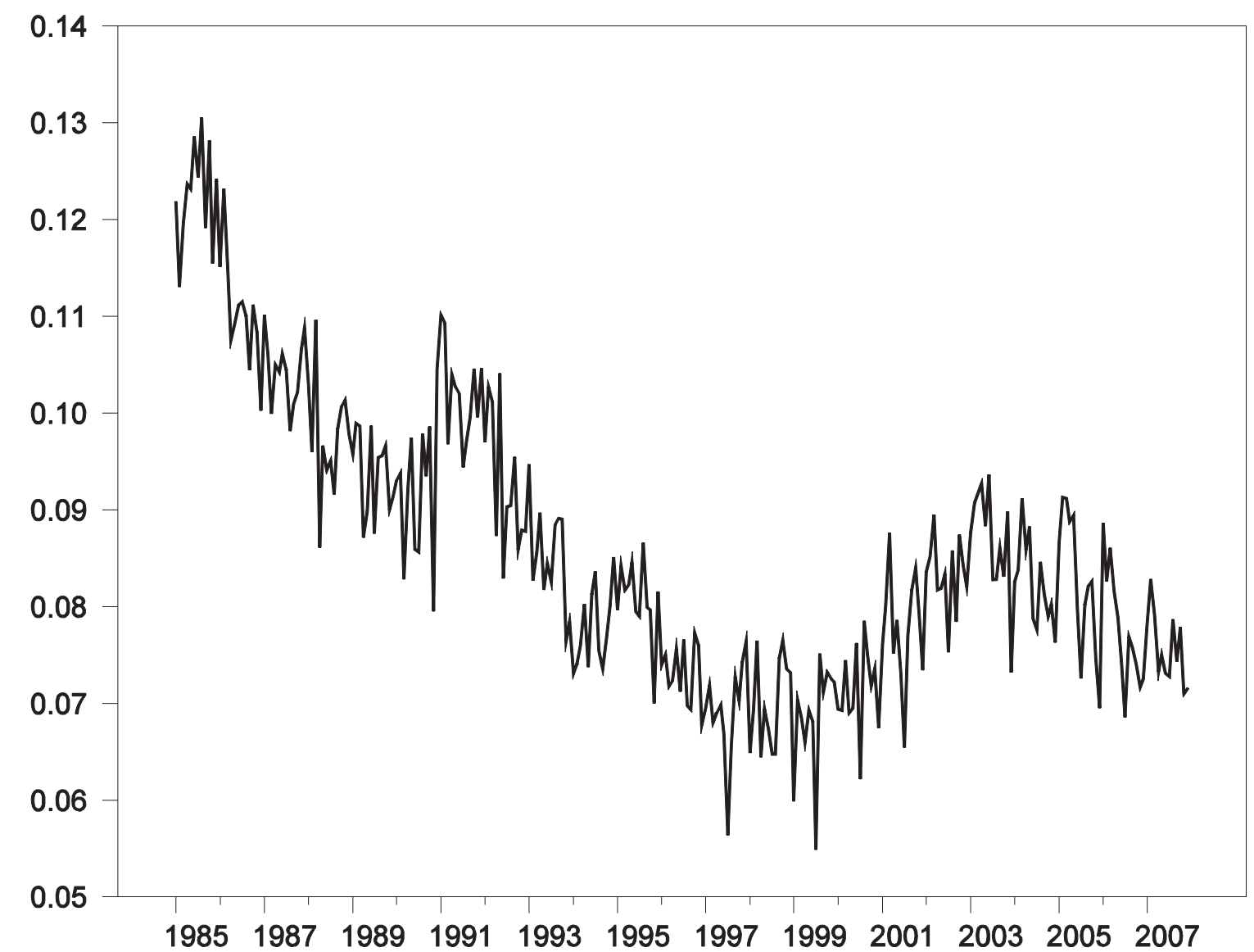


Figure 5 Rate of sale

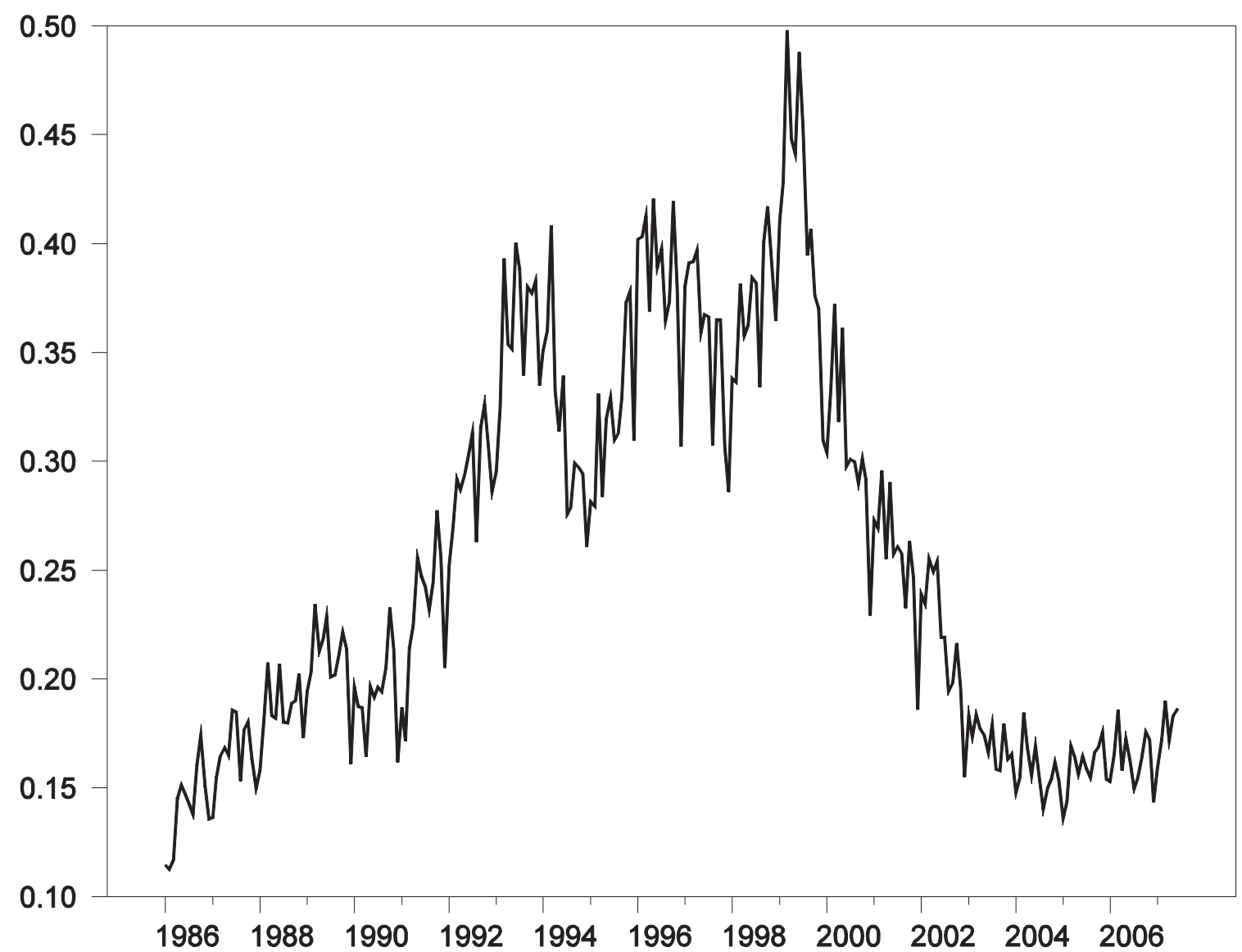

The rate of sale is expressed as the number of houses sold in the current month divided by the number of houses on the market at the start of the month. 
Figure 6: Number of houses sold, number of houses for sale and rate of sale, percentage changes

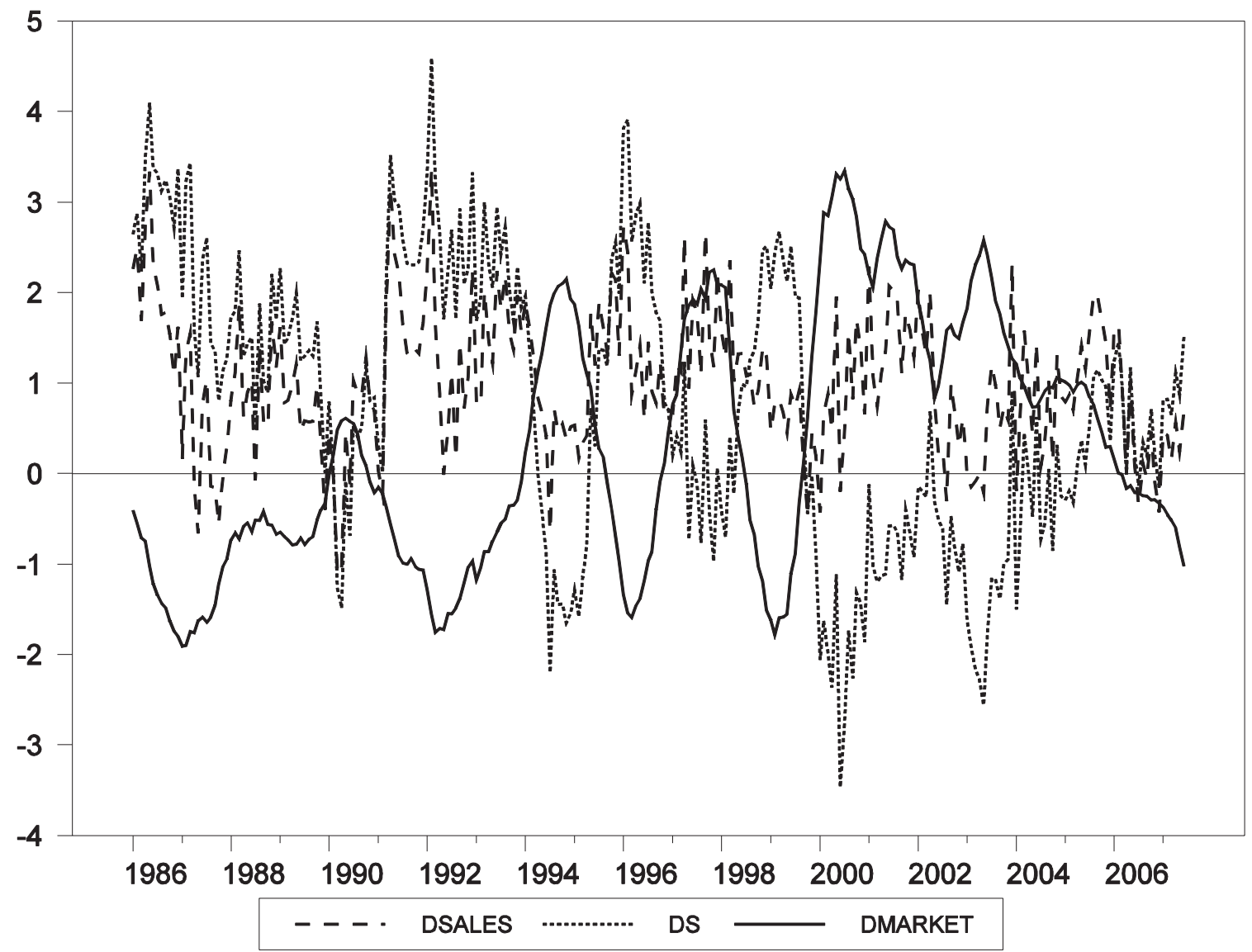

DSALES is the 12 month average of the change in the number of houses sold in each month, DS is the 12 month average of the change in the rate of sale, DMARKET is the 12 month average of the monthly change in the number of houses on the market. 
Figure 7: Rates of entry, sale and withdrawal (12 month moving averages)

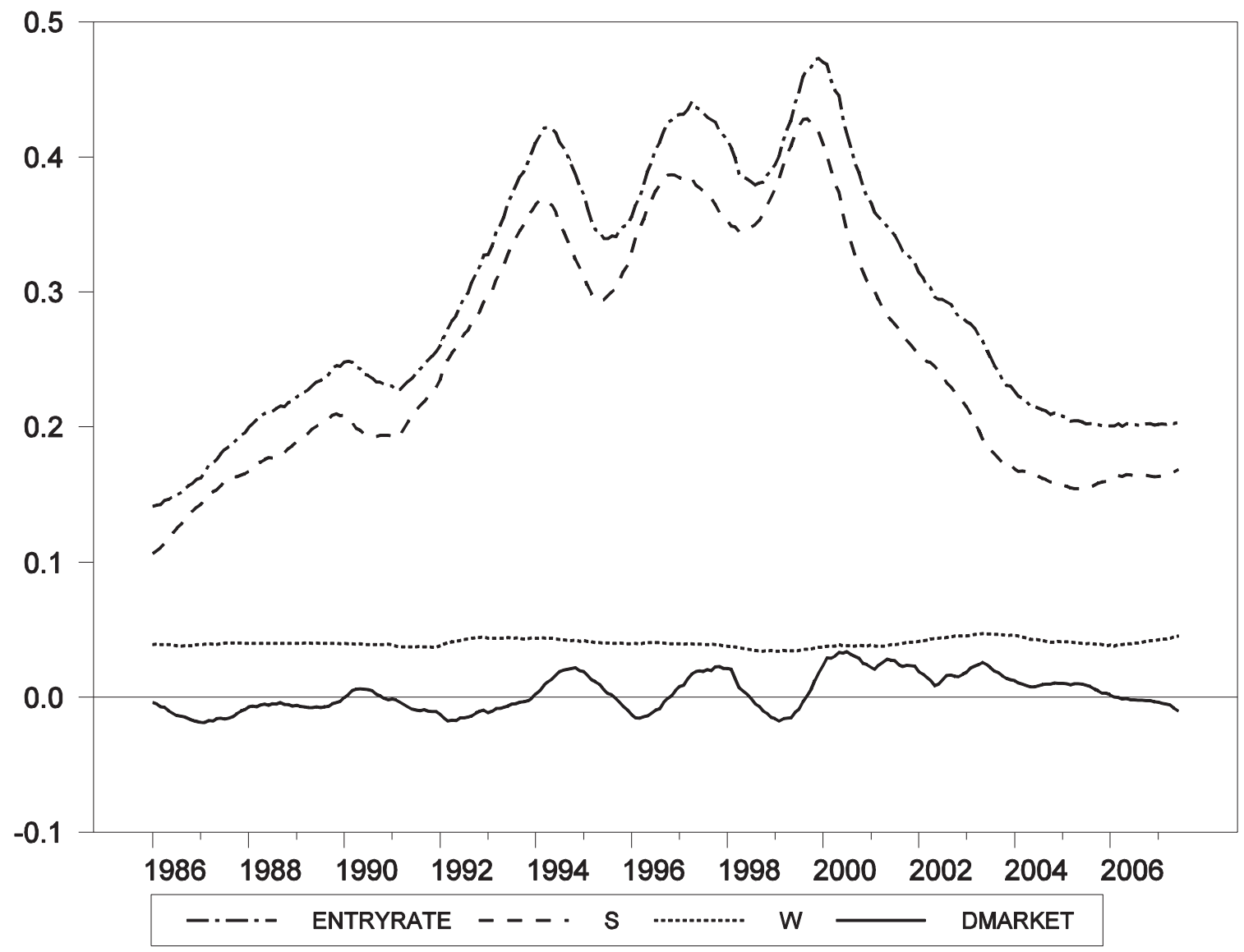

ENTRYRATE is expressed as the number of houses which entered the market in the current month divided by the number of houses on the market at the start of the month, $\mathrm{S}$ is the rate of sale and is expressed as the number of houses which sold in the current month divided by the number of houses on the market at the start of the month, $\mathrm{W}$ is the rate of withdrawal and is expressed as the number of houses which were withdrawn from the market in the current month divided by the number of houses on the market at the start of the month, DMARKET is the monthly change in the number of houses on the market. All series are 12 month averages. 
Figure 8: Rate of entry (number of new houses for sale divided by total stock of houses)

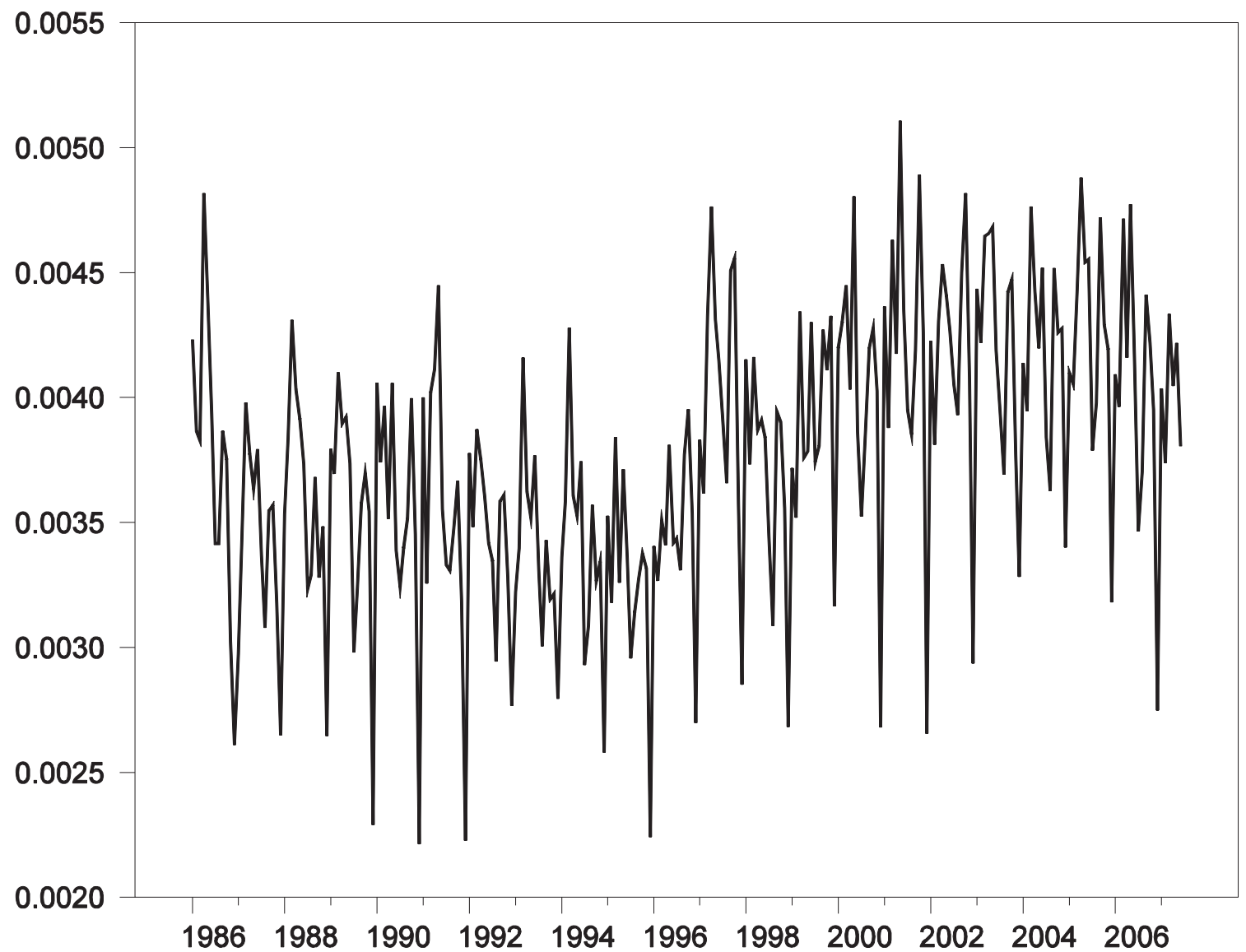

The rate of entry is expressed as the number of houses which entered the market in the current month divided by the total housing stock at the start of the month. 
Figure 9: Unemployment rate, percent

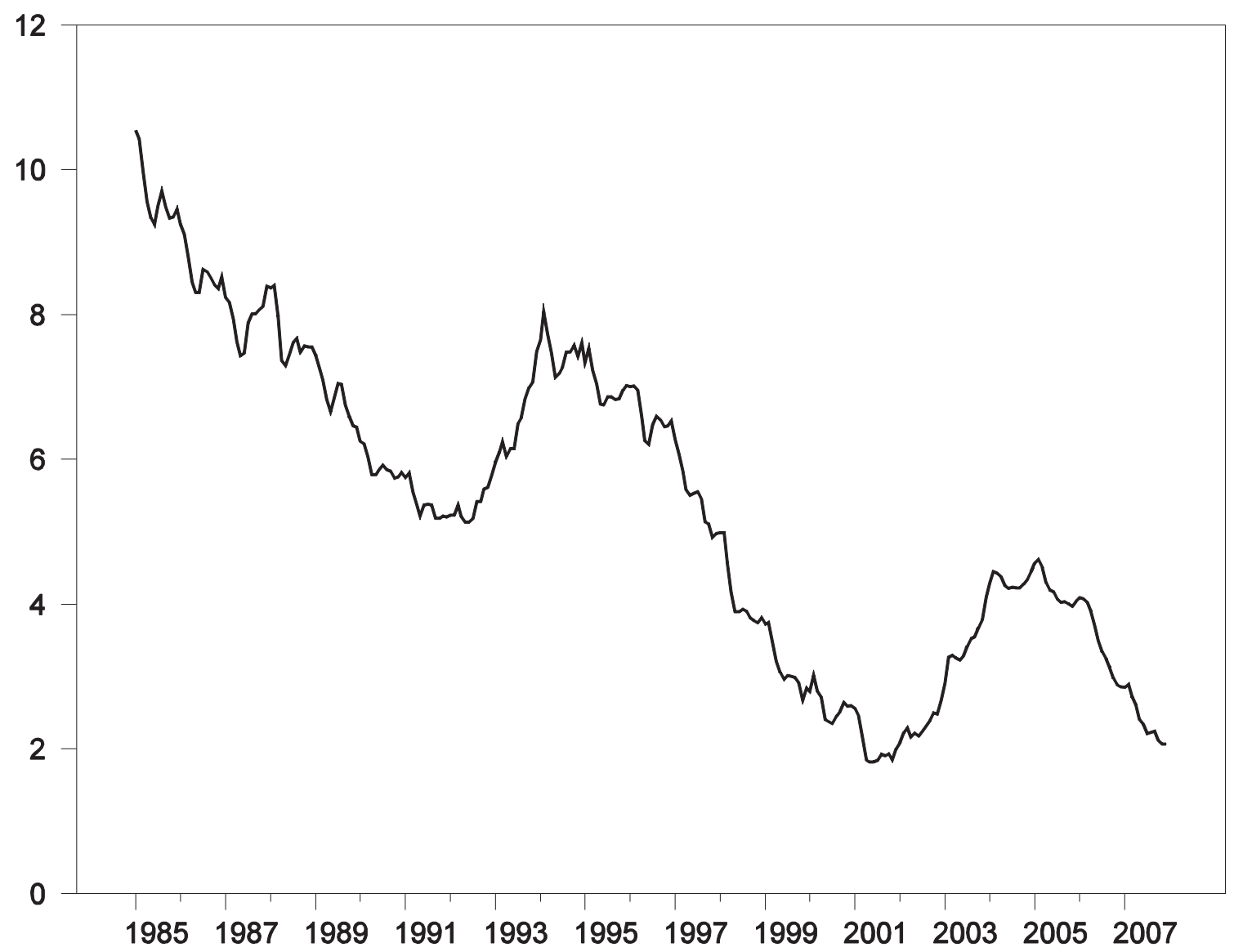


Figure 10: Mortgage interest rate, nominal and real, percent

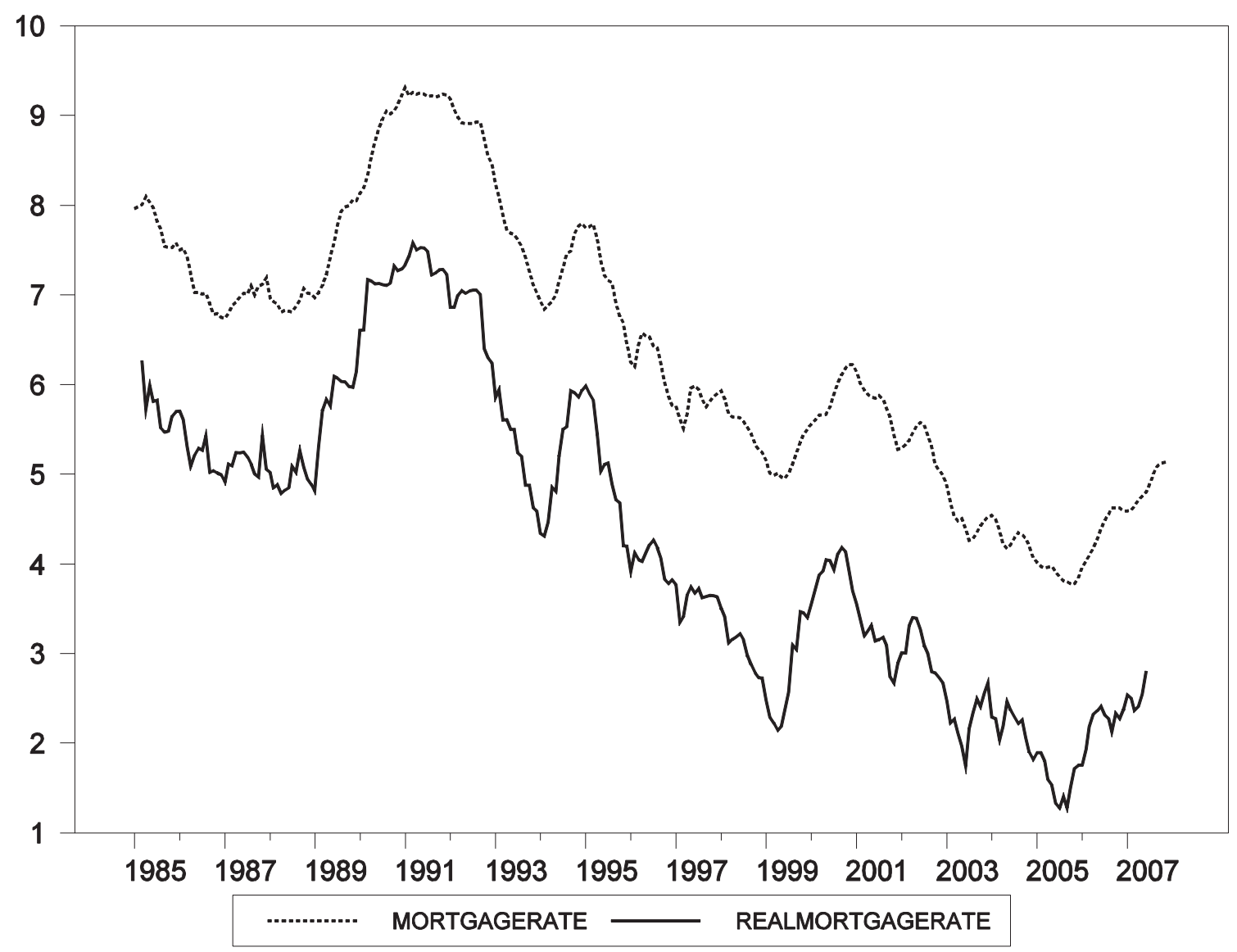

MORTGAGERATE is the mean nominal interest rate on all 5 year mortgages issued in the current month. REALMORGAGERATE is equal to MORTGAGERATE minus a measure of 5 year inflation expectations. Inflation expectations are constructed based on an ARMA(7,7) model of CPI inflation. 
Figure 11 a: The residual from cointegrating relation (2)

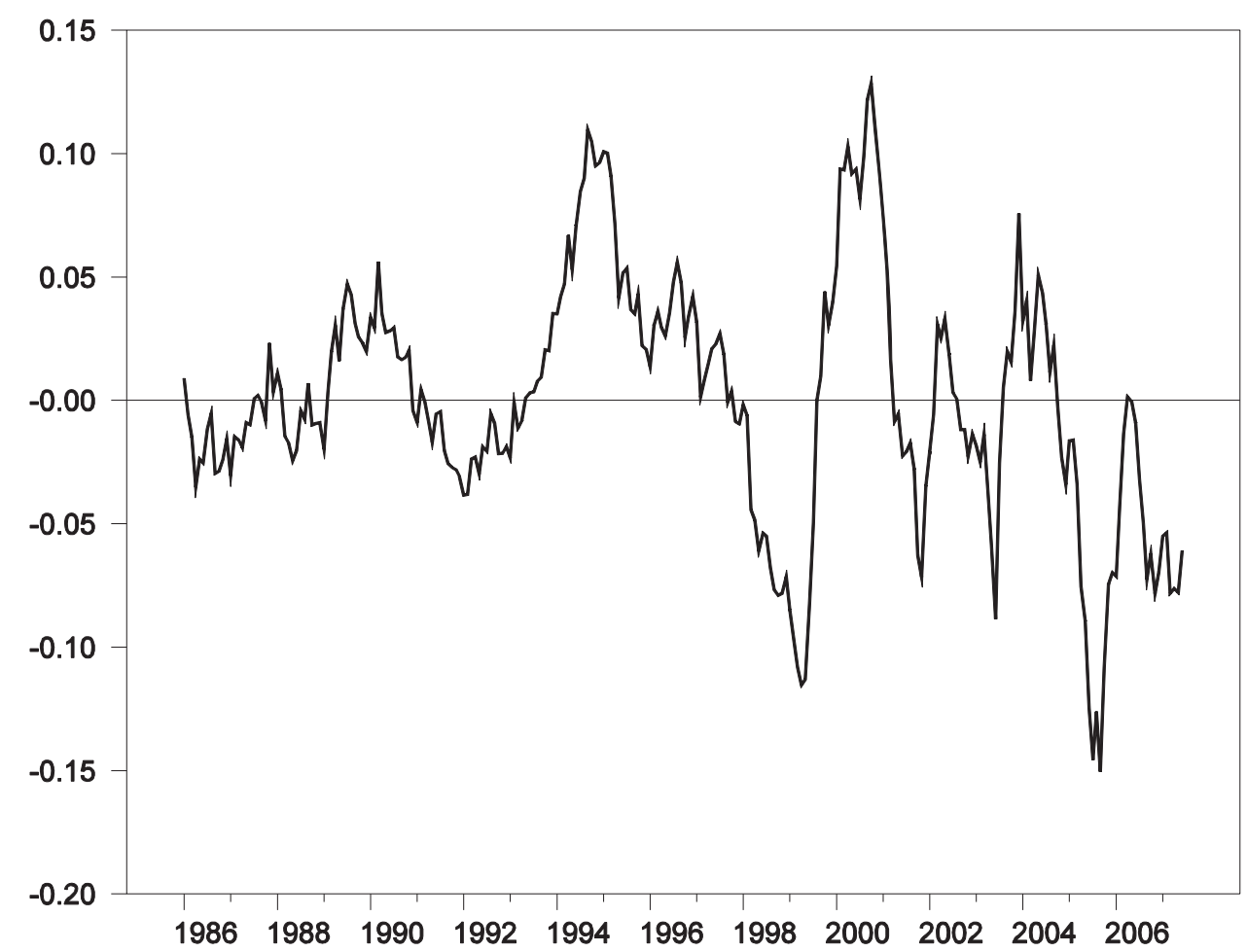

Figure 11b: The residual from cointegrating relation (3)

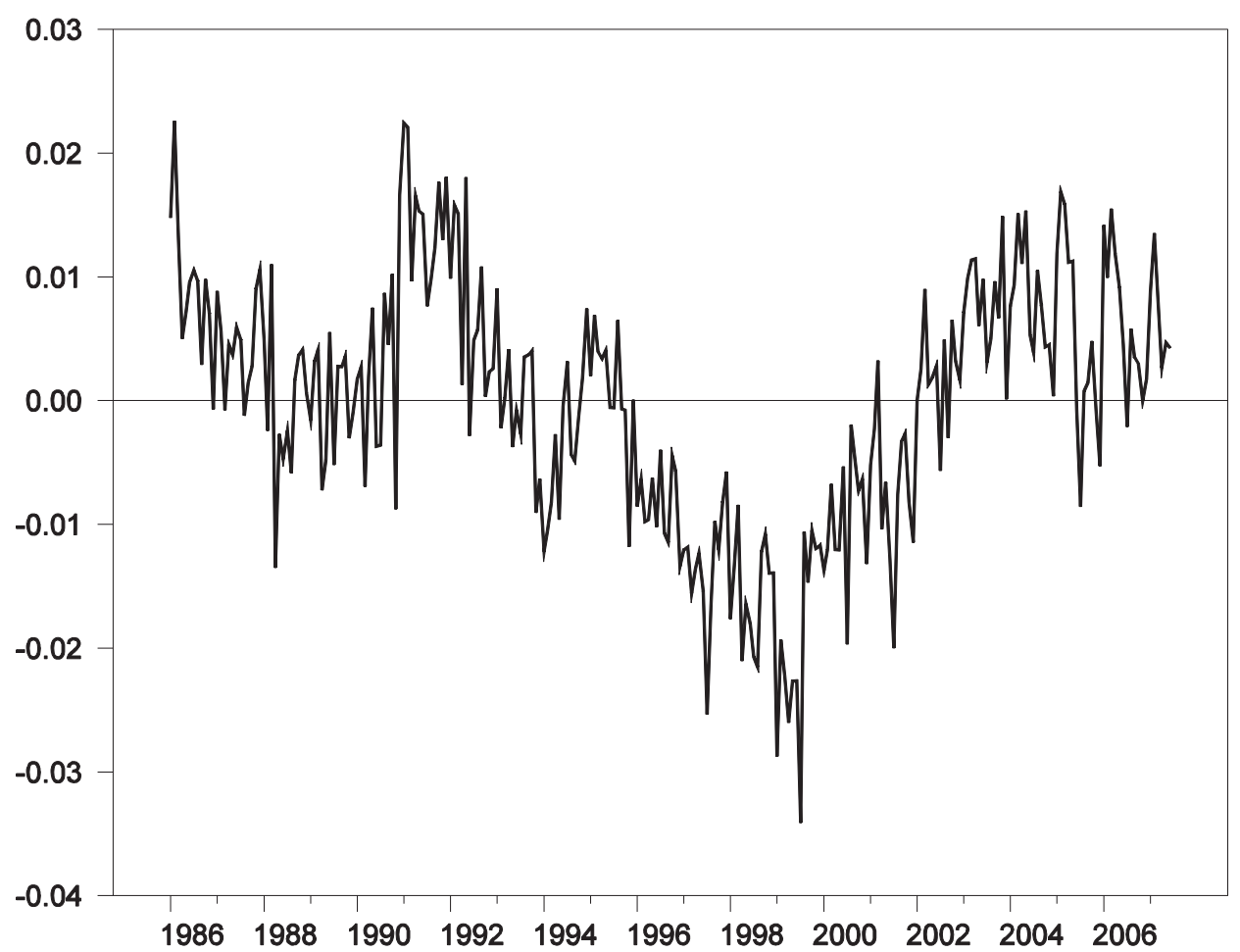


Figure 11c The residual from cointegrating relation (4)

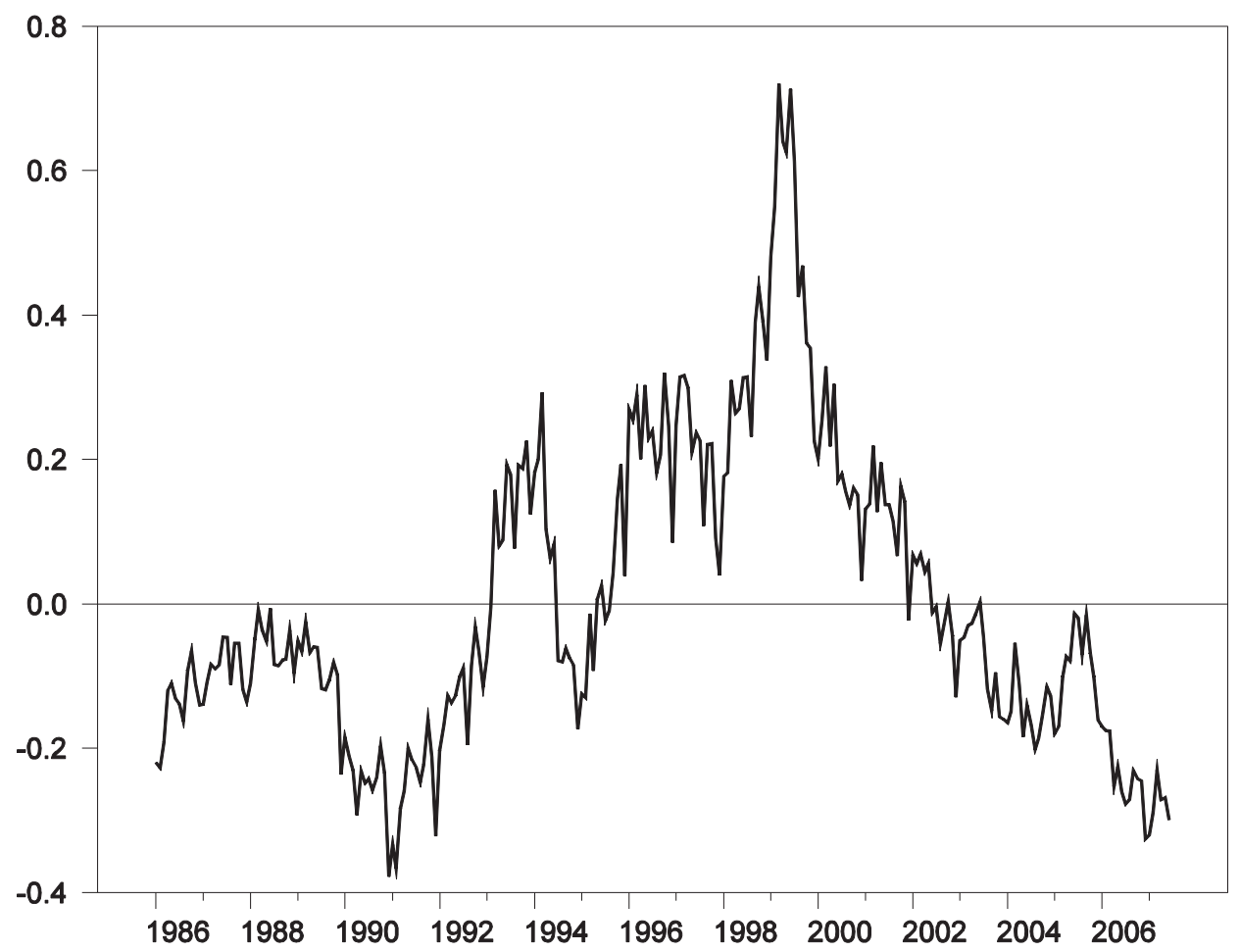


Figure 12a: Response of transaction price to an interest shock with 90 percent confidence intervals

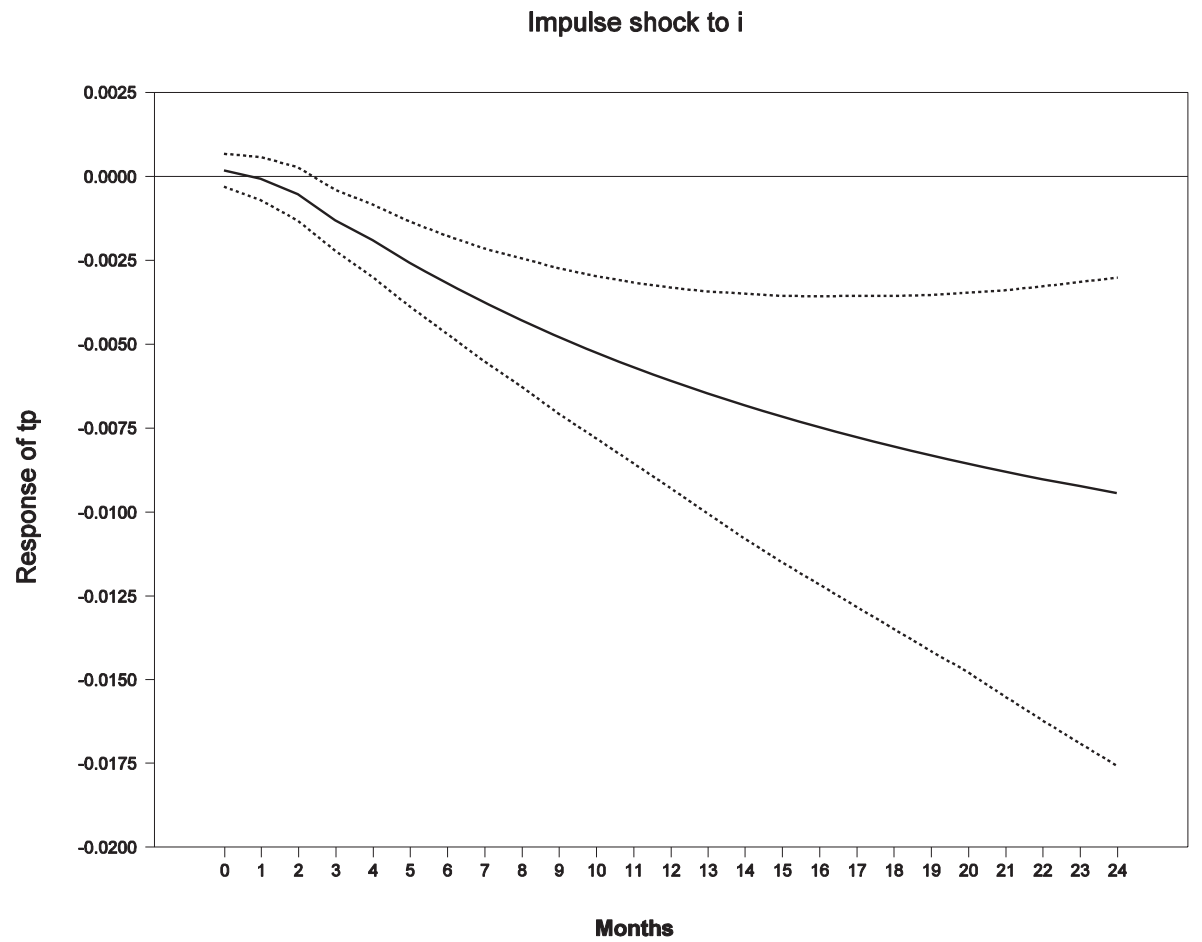

Figure 12b: Response of rate of sale to an interest shock with 90 percent confidence intervals

Impulse shock to

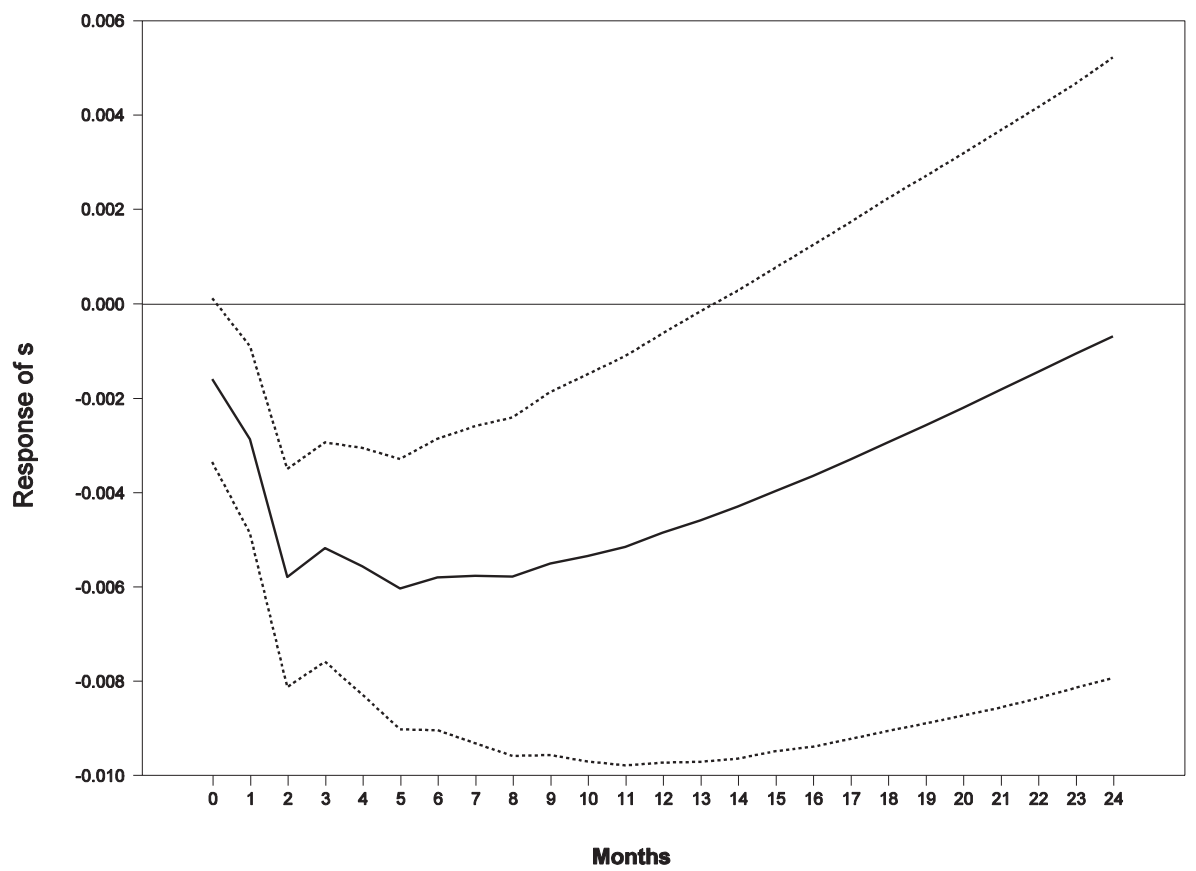


Figure 13: Decomposition of the forecast-error variance in the transaction price index with 90 percent confidence intervals

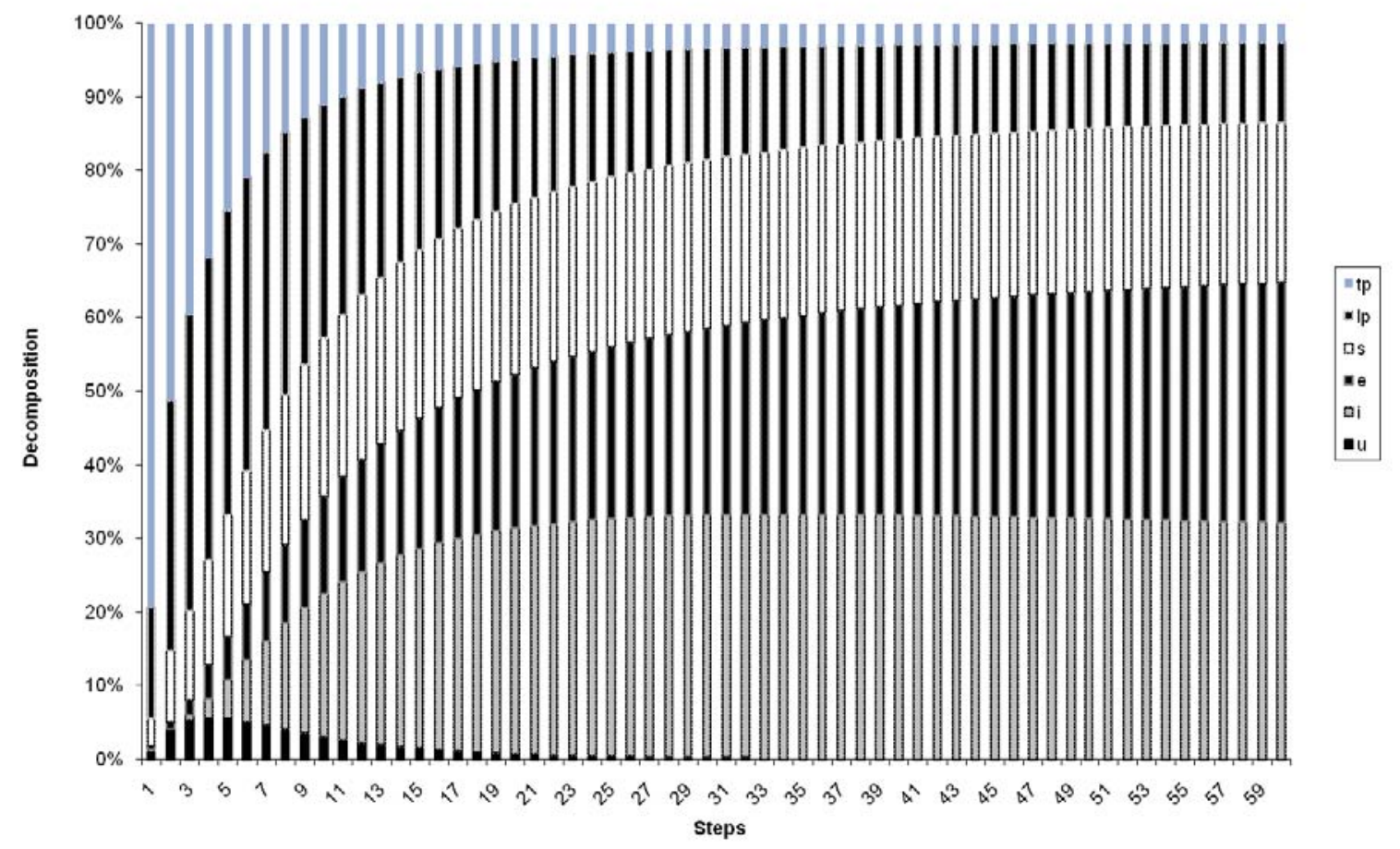

Figure 14: Decomposition of the forecast-error variance in the rate of sale

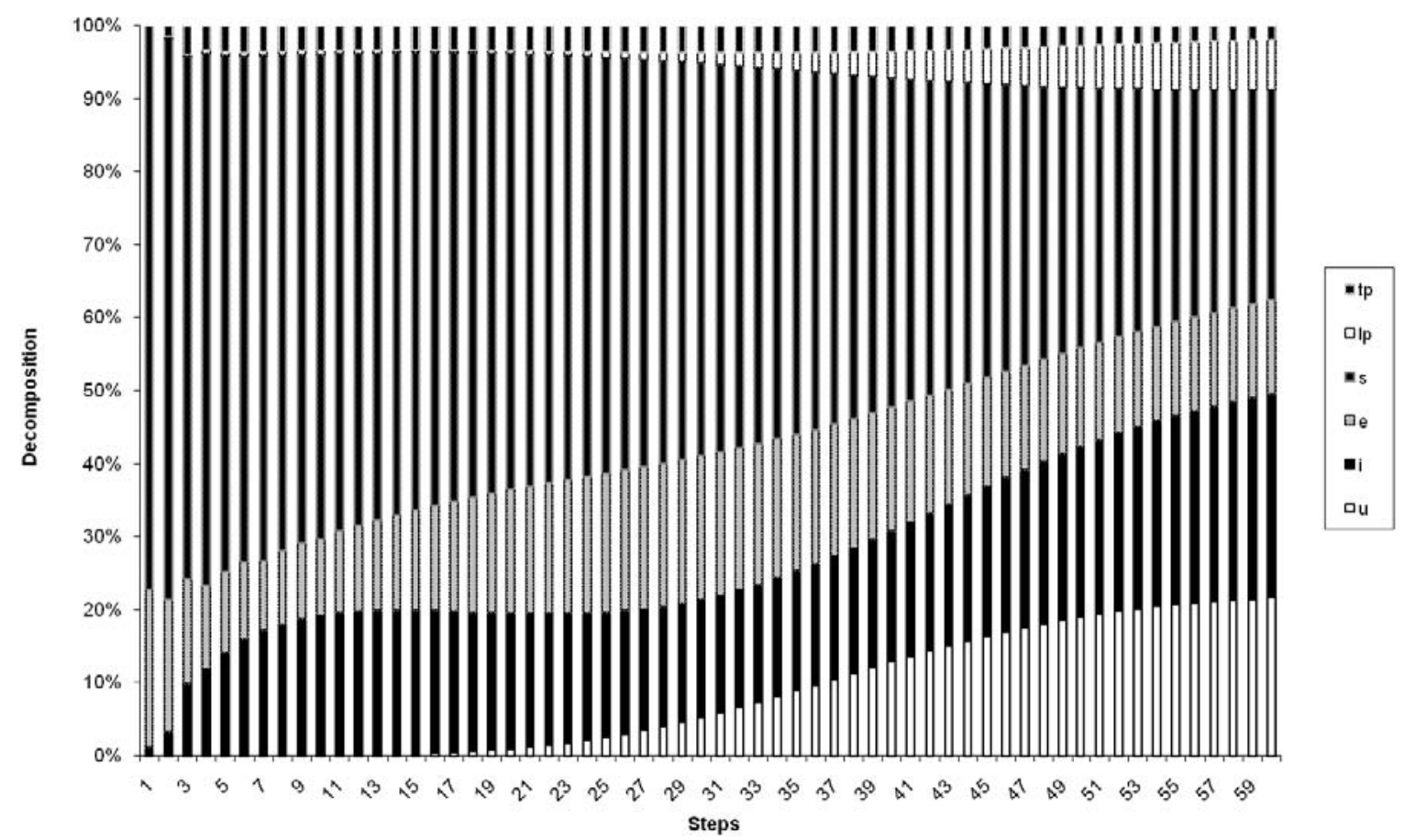




\section{References}

Andrew, M. and G. Meen (2003), "House price appreciation, transactions and structural change in the British housing market: a macroeconomic perspective", Real Estate Economics 31, 99-116.

Anglin, P., R. Rutherford, and T.M. Springer (2003), "The trade-off between the selling price of residential properties and time-on-the-market: the impact of price setting", Journal of Real Estate Finance and Economics 26, 95-111.

Berkovec, J.A. and J.L. Goodman (1996), "Turnover as a measure of demand for existing homes", Real Estate Economics 24, 421-440.

Boelhouwer, P.J., M.E.A. Haffner, P. Neuteboom, and P. de Vries (2001), "Koopprijsintwikkeling en de fiscale behandeling van het eigen huis", Technical Report, OTB Delft.

Clayton, J., N. Miller, and L. Peng (2008), "Price-volume correlation in the housing market: causality and co-movements", Journal of Real Estate Finance and Economics

De Wit, E.R. (2009), "Competing risks in a time-on-the-market analysis", manuscript, University of Amsterdam.

De Wit, E.R. and B. van der Klaauw (2009), "Asymmetric information in the housing market: evidence from list price reductions", manuscript, University of Amsterdam

den Reijer, A. (2006), “The Dutch business cycle: which indicators should we monitor?", DNB working paper no. 100.

Engelhardt, G.V. (2003), "Nominal loss aversion, housing equity constraints, and household mobility: evidence from the United States", Journal of Urban Economics 53, 171-195.

Francke. M. K., S. Vujić, and G. A. Vos, (2009), "Evaluation of house price models using an ECM approach: the case of the Netherlands", manuscript, University of Amsterdam.

Genesove, D. and C. Mayer (1997), "Equity and time to sale in the real estate market", American Economic Review 87, 255-269.

Genesove, D. and C. Mayer (2001), "Loss aversion and selling behavior: evidence from the housing market", Quarterly Journal of Economics 116, 1233-1260.

Glower, M., D.R. Haurin, and P.H. Hendershott (1998), "Selling price and selling time: the impact of seller motivation", Real Estate Economics 26, 719-740.

Haurin, D.R. (1988), "The duration of marketing time of residential housing", Journal of the American Real Estate and Urban Economics Association 16, 396-410.

Horowitz, J.L. (1992), "The role of list price in housing markets: theory and an econometric model", Journal of Applied Econometrics 7, 115-129.

Hort, K. (2000), "Prices and turnover in the market for owner-occupied homes", Regional Science and Urban Economics 30, 99-119.

Johansen, S. (1996), "Likelihood-based inference in Cointegrated Vector Autoregressive Models", $2^{\text {nd }}$ printing. Oxford University Press.

Knight, J. (2002), "Listing price, time on the market, and ultimate selling price: causes and effects of listing price changes", Real Estate Economics 30, 213-237.

Knight, J., C.F. Sirmans, and G. Turnbull (1994), "List price signaling and buyer behavior in the housing market", Real Estate Economics 30, 213-237.

Krainer, J. (2001), "A theory of liquidity in residential real estate markets", Journal of Urban Economics 49, 32-53.

Kranendonk, H. and J. Verbruggen (2008), “Are houses overvalued in the Netherlands", Technical Report no. 200, Netherlands Bureau for Economic Policy Analysis.

Leung, C.K.Y. and D. Feng (2005), "What drives the property price-trading volume correlation? Evidence from a commercial real estate market", Journal of Real Estate Finance and Economics 31, 241-255. 
Lütkepohl, H. (2006), New Introduction to Multiple Time Series Analysis, $2^{\text {nd }}$ printing, Berlin: Springer-Verlag, 2006.

Miller, N.G. and M.A. Sklarz (1986), “A note on leading indicators of housing market price trends", Journal of Real Estate Research 1, 99-109.

Ngai, R. and S. Tenreyro (2009), "Hot and Cold Seasons in the Housing Market", manuscript, London School of Economics.

Novy-Marx, R. (2009), "Hot and cold markets", Real Estate Economics 37, 1-22.

Ortalo-Magné, F. and S. Rady (1999), "Boom in, bust out: Young households and the housing price cycle", European Economic Review 43, 755-766.

Ortalo-Magné, F. and S. Rady (2004), "Housing transactions and macroeconomic fluctuations: a case study of England and Wales", Journal of Housing Economics13, 287-303.

Ortalo-Magné, F. and S. Rady (2006), "Housing market dynamics: on the contribution of income shocks and credit constraints", Review of Economic Studies 73, 459-485.

Rosenthal, L. (2006), "Efficiency and seasonality in the UK housing market, 1991-2001", Oxford Bulletin of Economics and Statistics 68, 289-317.

Said, S. E. and D. A. Dickey (1984), "Testing for unit roots in autoregressive-moving average models of unknown order", Biometrika 71(3), 599-607

Sims, C. A. and T. Zha (1999), "Error bands for impulse responses", Econometrica 67, 1113-1155.

Stein, J. (1995), "Prices and trading volume in the housing market. A model with downpayment constraints", Quarterly Journal of Economics 110, 379-406.

Wheaton, W. C. (1990), "Vacancy, search, and prices in a housing market matching model" Journal of Political Economy 98, 1270-1292.

Wheaton, W. C. and N. J. Lee (2009), "The co-movement of housing sales and housing prices: empirics and theory", paper presented at the ASSA meeting, San Francisco, January 2009.

Yavas, A. and S. Yang (1995), "The strategic role of listing price in marketing real estate: theory and evidence", Real Estate Economics 23, 347-368. 


\section{Appendix 1: Price index estimation}

We estimate indexes for transactions and list prices based on hedonic regressions of the type

$\log P_{i t m}=x_{i t m}^{\prime} \beta+\varepsilon_{i t m}$,

where $P_{i m t}$ denotes the price of house $i$ sold in month $m$ of year $t, x$ is a vector of characteristics including dummy variables indicating the month of sale. The $\beta$ vector contains marginal prices of the characteristics and log price indexes corresponding to the monthly dummies. We estimate separate equations year by year and chain them as follows. We compute the one-year return $r$ for a house with mean characteristics $\bar{x}_{t m}$ as follows. The yearover-year-return $r_{t m}$ of the price index in any year $t$ and calendar month $m$ is calculated as

$r_{t m}=\left(\bar{x}_{t-1, m}^{\prime} \hat{\beta}_{t}\right)-\left(\bar{x}_{t-1, m}^{\prime} \hat{\beta}_{t-1}\right)$,

The mean value $\bar{x}_{t-1, m}$ is based on the set of all sold houses in year $t-1$. We use this same set for both the transaction price index and the list price index so return differences between the transaction price index and the list price index can only be attributed to price differences and not to differences in characteristics. The $\log$ of the nominal price index $I_{t m}$ is then given by

$I_{t m}=\bar{x}_{0 m} \hat{\beta}_{0}+\sum_{\tau=1}^{t} r_{z m}$

As an example, Table A1 presents the hedonic regression for 1998 sales prices. Table A2 gives summary statistics for all regressions. 
Table A1: Hedonic regression of the log of transaction price on characteristics for 1998

\begin{tabular}{lcc} 
& & \\
\hline Constant & Coeff. & Std. Error \\
Log floor size & 9.678 & 0.217 \\
Log floor size squared & 0.145 & 0.040 \\
Log lot size & 0.062 & 0.004 \\
Log lot size squared & -0.039 & 0.001 \\
Number rooms & 0.005 & 0.000 \\
Typehouse2 & 0.018 & 0.001 \\
Typehouse3 & 0.127 & 0.005 \\
Typehouse4 & 0.043 & 0.002 \\
Typehouse5 & 0.148 & 0.003 \\
Typeapp1 & 0.357 & 0.003 \\
Typeapp2 & -0.048 & 0.005 \\
Typeapp3 & -0.102 & 0.005 \\
Typeapp4 & -0.120 & 0.006 \\
Typeapp5 & -0.088 & 0.005 \\
Typeapp6 & -0.104 & 0.005 \\
Typeapp7 & -0.266 & 0.018 \\
Lift & 0.032 & 0.017 \\
Building age unknown & 0.049 & 0.003 \\
Built 1500-1905 & 0.036 & 0.028 \\
Built 1906-1930 & 0.057 & 0.004 \\
Built 1931-1944 & -0.023 & 0.003 \\
Built 1945-1959 & -0.021 & 0.003 \\
Built 1960-1970 & -0.024 & 0.003 \\
Built 1971-1980 & -0.078 & 0.002 \\
Built 1991-2000 & -0.058 & 0.002 \\
Parking2 & 0.072 & 0.003 \\
Parking3 & 0.067 & 0.003 \\
Parking4 & 0.073 & 0.004 \\
Parking6 & 0.120 & 0.002 \\
Parking8 & 0.120 & 0.005 \\
Garden0 & 0.168 & 0.005 \\
Garden1 & -0.021 & 0.003 \\
Garden2 & -0.016 & 0.003 \\
Garden3 & -0.014 & 0.004 \\
Garden5 & -0.021 & 0.003 \\
Garden6 & 0.000 & 0.003 \\
Garden7 & 0.005 & 0.003 \\
Garden8 & -0.006 & 0.003 \\
Insulation & -0.006 & 0.004 \\
No heating & -0.011 & 0.002 \\
Gas or coal heater & -0.438 & 0.195 \\
Other central heating & -0.500 & 0.195 \\
Quiet road & -0.410 & 0.195 \\
Ground lease & 0.014 & 0.002 \\
Internal maintenance & -0.066 & 0.003 \\
Exterior maintenance & 0.024 & 0.001 \\
\hline R2 adjusted & 0.015 & 0.001 \\
Standard error of estimate & & 0.812 \\
Observations & & 0.195 \\
\hline & & \\
\hline
\end{tabular}




\section{Definitions for table A1}

$\begin{array}{ll}\text { House Type } & \\ \text { Typehouse1 } & 1 \text { if row house } \\ \text { Typehouse2 } & 1 \text { if back-to-back housing } \\ \text { Typehouse3 } & 1 \text { if corner house (hoekwoning) } \\ \text { Typehouse4 } & 1 \text { if semi-detached house } \\ \text { Typehouse5 } & 1 \text { if detached house } \\ \text { Apartment Type } & \\ \text { Typeapp1 } & 1 \text { if ground-level apartment } \\ \text { Typeapp2 } & 1 \text { if top-level apartment } \\ \text { Typeapp3 } & 1 \text { if maisonette } \\ \text { Typeapp4 } & 1 \text { if staircase-access flat } \\ \text { Typeapp5 } & 1 \text { if gallery flat } \\ \text { Typeapp6 } & 1 \text { if old-age housing } \\ \text { Typeapp7 } & 1 \text { if two-floor apartment } \\ \text { Parking } & 1 \text { if no parking place } \\ \text { Parking0 } & 1 \text { if outdoor parking place } \\ \text { Parking2 } & 1 \text { if carport and garage } \\ \text { Parking3 } & 1 \text { if carport but no garage } \\ \text { Parking4 } & 1 \text { if garage but no carport } \\ \text { Parking6 } & 1 \text { if garage for more than one car } \\ \text { Parking8 } & \\ \text { Garden } & 1 \text { if no garden } \\ \text { Garden0 } & 1 \text { if garden facing north } \\ \text { Garden1 } & 1 \text { if garden facing north-east } \\ \text { Garden2 } & 1 \text { if garden facing east } \\ \text { Garden3 } & 1 \text { if garden facing south-east } \\ \text { Garden4 } & 1 \text { if garden facing south } \\ \text { Garden5 } & 1 \text { if garden facing south-west } \\ \text { Garden6 } & 1 \text { if garden facing west } \\ \text { Garden7 } & 1 \text { if garden facing north-west } \\ \text { Garden8 } & \\ \text { Maintenance } & \\ \text { Interior and exterior maintenance are assessed on a scale from } 1 \text { to } 9 \\ \text { Location } & \\ 76 \text { regional dummies are included } \\ \end{array}$


Table A2: Summary Statistics, all Hedonic Regressions

Transaction Price

List Price

\begin{tabular}{c|ccc|ccc}
\hline Year & R2adj & Std.err of estimate & Obs. & R2adj & Std.err of estimate & Obs. \\
\cline { 2 - 6 } 1985 & 0.812 & 0.197 & 18640 & 0.799 & 0.216 & 25210 \\
1986 & 0.814 & 0.191 & 23739 & 0.803 & 0.208 & 28300 \\
1987 & 0.813 & 0.199 & 24102 & 0.802 & 0.216 & 27926 \\
1988 & 0.807 & 0.201 & 25141 & 0.796 & 0.216 & 29291 \\
1989 & 0.807 & 0.204 & 27134 & 0.801 & 0.216 & 30235 \\
1990 & 0.811 & 0.203 & 25398 & 0.802 & 0.216 & 29656 \\
1991 & 0.814 & 0.197 & 29991 & 0.809 & 0.211 & 33654 \\
1992 & 0.813 & 0.191 & 33527 & 0.807 & 0.208 & 36610 \\
1993 & 0.815 & 0.180 & 38052 & 0.808 & 0.197 & 41588 \\
1994 & 0.824 & 0.176 & 37181 & 0.810 & 0.192 & 41380 \\
1995 & 0.826 & 0.177 & 51991 & 0.817 & 0.193 & 59223 \\
1996 & 0.828 & 0.177 & 63683 & 0.826 & 0.186 & 69499 \\
1997 & 0.827 & 0.181 & 73497 & 0.806 & 0.201 & 82621 \\
1998 & 0.812 & 0.195 & 83485 & 0.807 & 0.207 & 89555 \\
1999 & 0.806 & 0.211 & 90690 & 0.776 & 0.246 & 100115 \\
2000 & 0.806 & 0.218 & 92076 & 0.770 & 0.260 & 106265 \\
2001 & 0.805 & 0.210 & 101148 & 0.786 & 0.247 & 112126 \\
2002 & 0.809 & 0.199 & 94873 & 0.798 & 0.238 & 123973 \\
2003 & 0.814 & 0.194 & 96651 & 0.804 & 0.226 & 143185 \\
2004 & 0.810 & 0.199 & 124173 & 0.790 & 0.232 & 167671 \\
2005 & 0.809 & 0.198 & 141971 & 0.800 & 0.223 & 176290 \\
2006 & 0.813 & 0.203 & 144303 & 0.787 & 0.238 & 175441 \\
2007 & 0.813 & 0.207 & 144450 & 0.766 & 0.253 & 160818 \\
\hline Average & 0.813 & 0.196 & - & 0.799 & 0.219 & - \\
St.dev & 0.007 & 0.012 & - & 0.014 & 0.020 & - \\
Total & - & - & 1585897 & - & - & 1890633 \\
\hline
\end{tabular}




\section{Appendix 2: Inferring the market rate of entry}

The sales covered by our data include only properties sold by NVM. Since the market share of NVM has varied over the years this may bias our measure of the rate of entry. To account for this we first measure the NVM market share. Statistics on the total number of sales in the Netherlands only exist from 1993 through the Dutch land registry. the Kadaster. In order to backcast sales from 1985 we run an OLS regression on data from 1993:1-2005:12 data for $\log$ (\#MarketSales) against $\log ($ real GDP) and monthly dummies. The results are given below

\begin{tabular}{ccc}
\hline \hline Variable & Coefficient & Std. Error \\
\hline \hline LOG(REALGDP) & 0.975430 & 0.056107 \\
D2 & 0.107217 & 0.031324 \\
D3 & 0.283353 & 0.031324 \\
D4 & 0.271763 & 0.031324 \\
D5 & 0.328597 & 0.031324 \\
D6 & 0.306609 & 0.031324 \\
D7 & 0.461724 & 0.031324 \\
D8 & 0.379500 & 0.031324 \\
D9 & 0.311551 & 0.031324 \\
D10 & 0.364873 & 0.031324 \\
D11 & 0.333500 & 0.031324 \\
D12 & 0.679455 & 0.031324 \\
C & -4.524174 & 0.694360 \\
\hline \hline Adjusted R-squared & 0.854919 & \\
S.E. of regression & 0.079860 & \\
Durbin-Watson stat & 1.366961 & \\
\hline
\end{tabular}

The Kadaster sales data has a seasonal pattern not found in the NVM. There is also a time lag between the NVM information dated at the time of signing the contract and the subsequent register date in the Kadaster. To take this into account we measure the NVM market share by using 12 month moving averages lagging the NVM observations three months relative to the Kadaster numbers. Denoting the NVM market share of sales by $\alpha_{t}$ we have

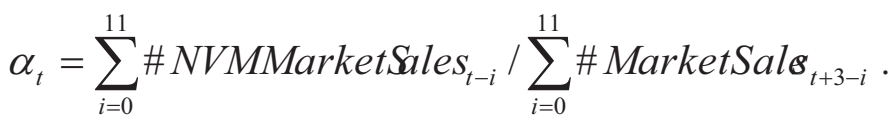

We have data on entry and exit of NVM properties. We also know the total number of sales and can calculate the NVM market share (in terms of sales). We want to use these data to infer entry and exit rates on the market level.

Next we want to measure the market share of entry. To simplify, and since we do not have information that would justify another assumption, we assume that $\alpha$ also applies to the number of houses on the market. We assume that the rates of entry, sale and withdrawal are the same for all brokers, implying 
that the increasing market share of NVM reflects an increased number of members, not that NVM brokers are different.

Defining the market rate of entry as

$\mathrm{e}_{\mathrm{t}}=$ Entry $_{\mathrm{t}} /$ Stock $_{\mathrm{t}}$

The observed amount of entry (superscript $\mathrm{N}$ to denote NVM) can then be expressed as

Entry $_{t}^{N}=e_{t}$ Stock $_{t}^{N}+e_{t}^{\Delta}$ Stock $_{t}^{N}$

where $e_{t}^{\Delta}=\frac{\alpha_{t}^{e}-\alpha_{t-1}^{e}}{\alpha_{t-1}^{e}}$ denotes the extra entry rate from new brokers and $\alpha_{t}^{e}$ denotes the NVM market share of entry. Inserting this into the above equation and solving for $e$ yields

$e_{t}=\frac{\text { Entry }_{t}^{N}}{\text { Stock }_{t}^{N}}-\frac{\alpha_{t}^{e}-\alpha_{t-1}^{e}}{\alpha_{t-1}^{e}}$

The conclusion is that we should adjust the observed entry rate by deducting the relative increase of NVM market share. Furthermore. we do not observe the NVM market share of properties entering the market. We approximate this by the lagged market share of sold dwellings.

$\alpha_{t}^{e}=\alpha_{t-x_{t}}$

where $x_{t}$ is the average time till sale in month $t$ (measured in months) rounded to the nearest integer. The figure below displays the NVM market share of sold properties and the NVM market share of properties entering the market.

The figure below displays the resulting corrected rate of entry along with the uncorrected series. 


\section{Appendix 3. Impulse Response Functions}

In this appendix we present graphs of the response of the variables of the system to Choleski orthogonalized shocks, according to four different orderings as defined in the main text. Each column represents a shock and each row an endogenous variable. Included are $90 \%$ confidence intervals.

Table A1: Impulse responses. Ordering 1

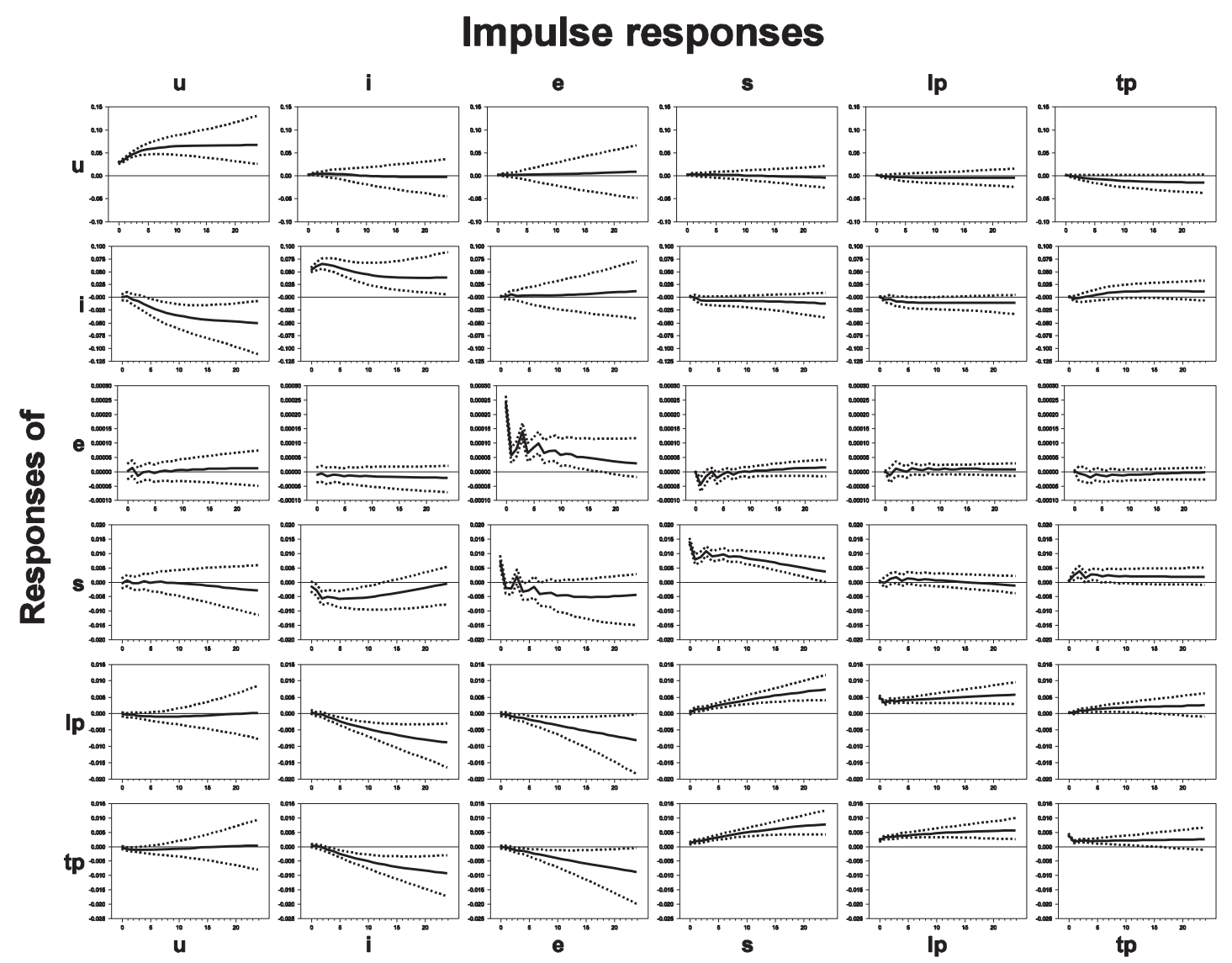


Table A2: Impulse responses. Ordering 2

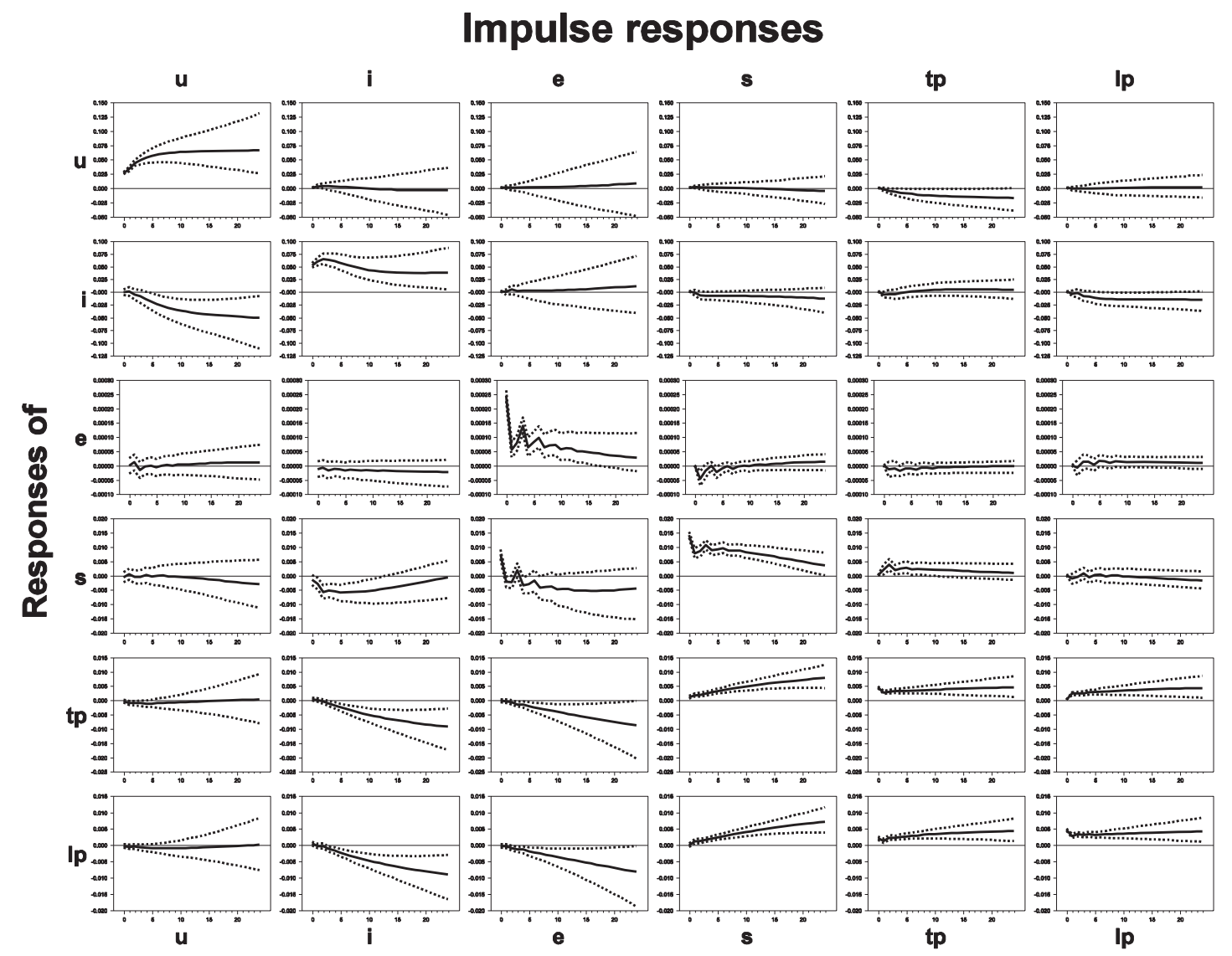


Table A3: Impulse responses. Ordering 3

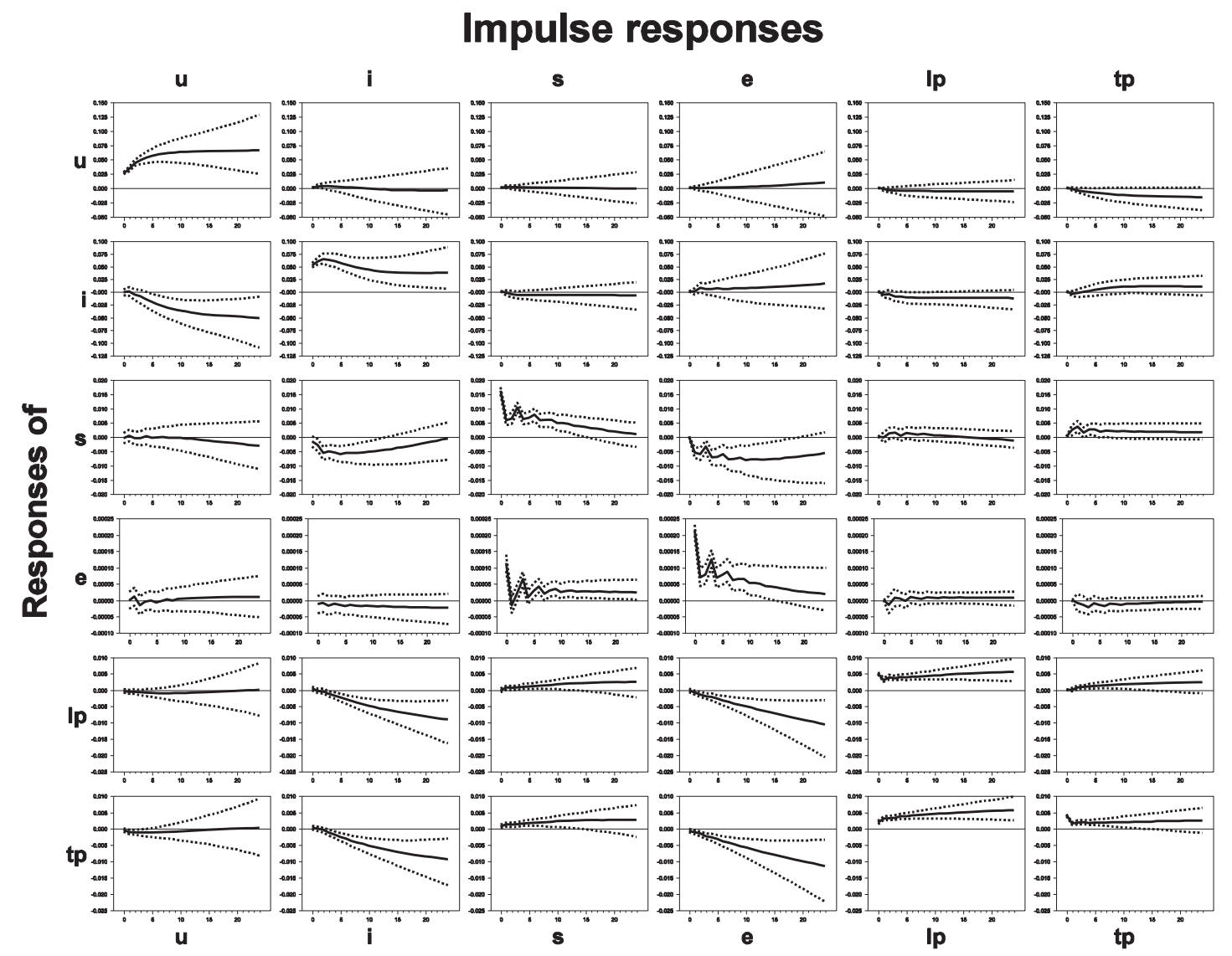


Table A4: Impulse responses. Ordering 4

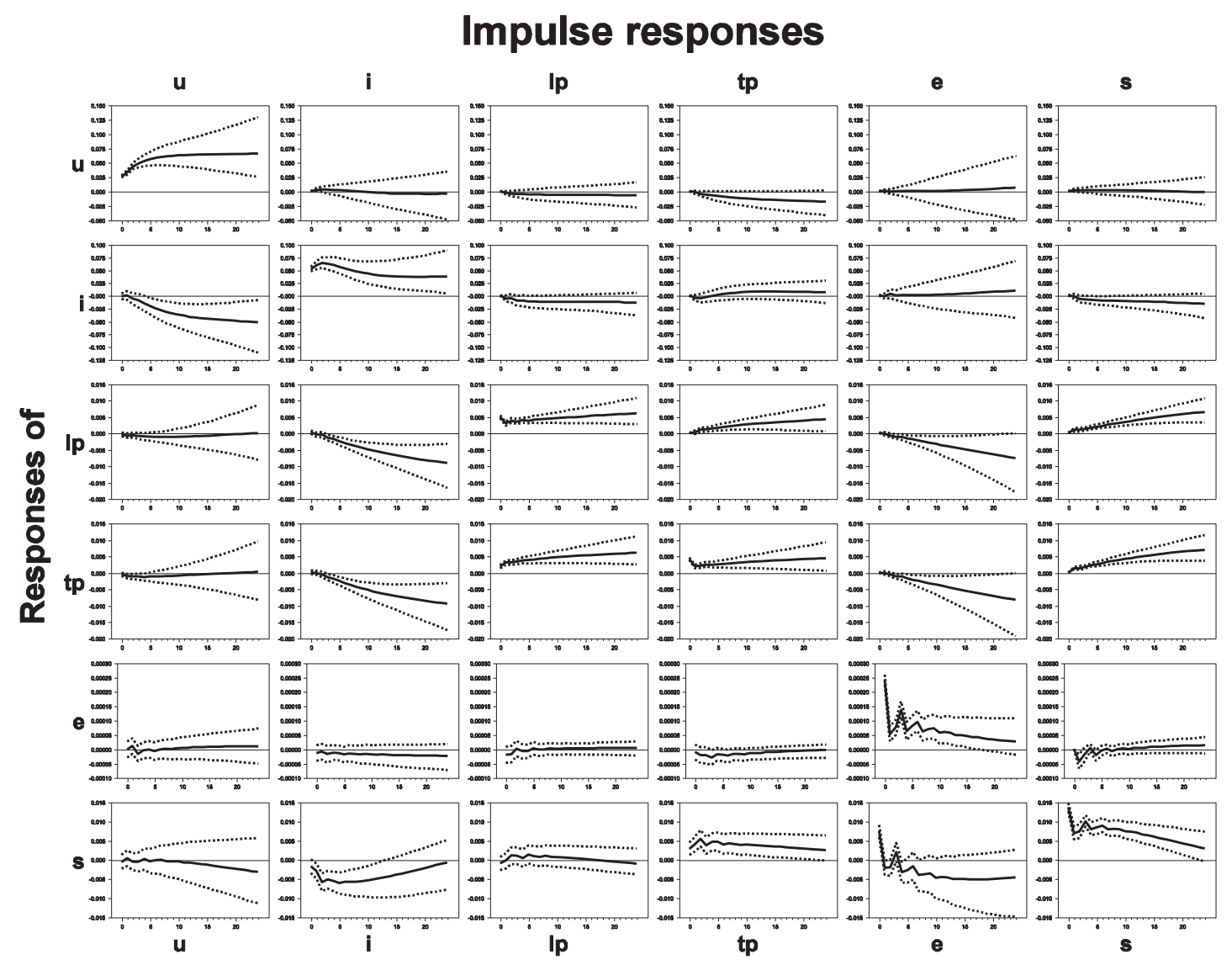


Table A5: Impulse responses. Ordering 1, unrestricted cointegrating vectors

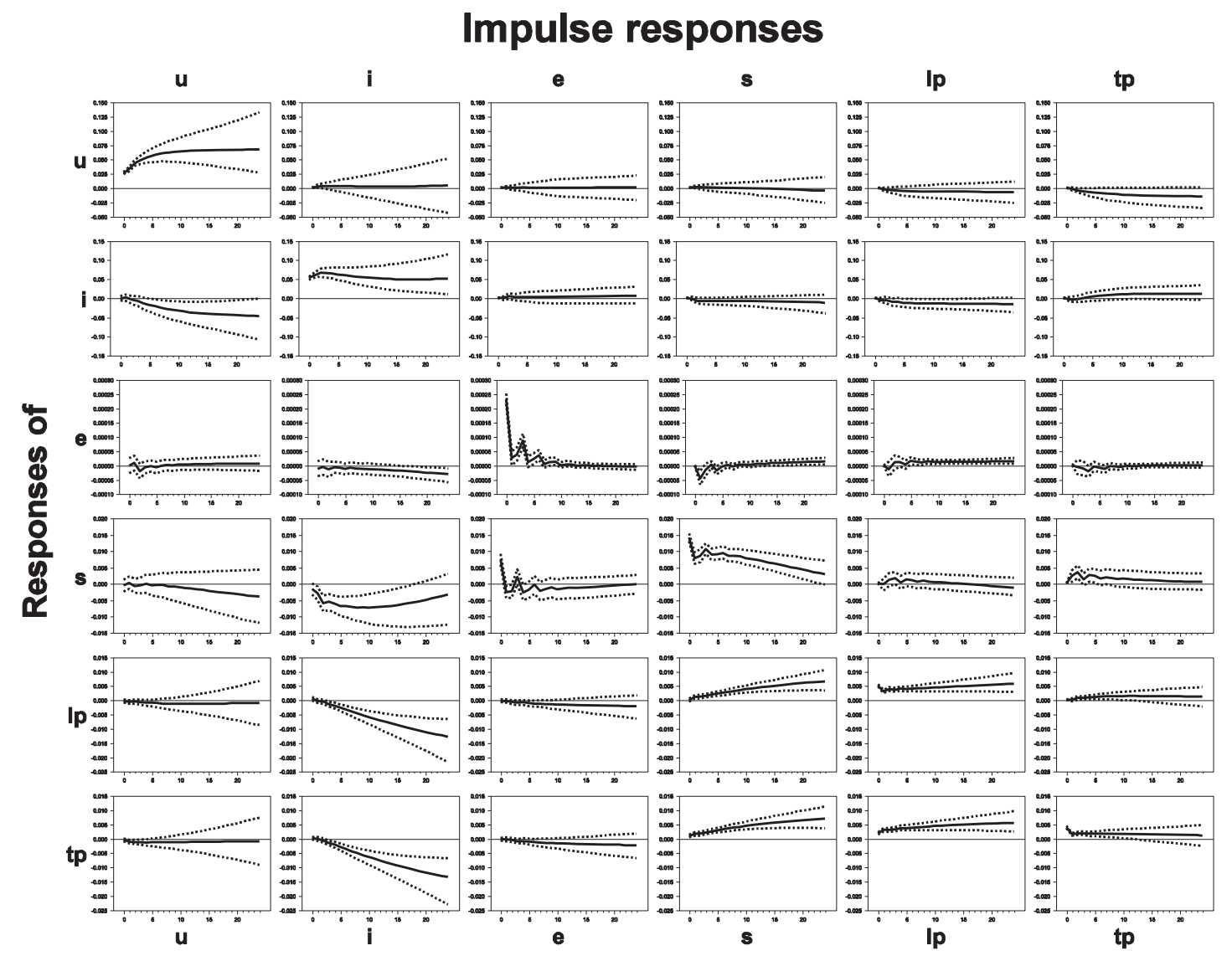

